\title{
The Influence of Synthesis Parameters on Structural and Magnetic Properties of Iron Oxide Nanomaterials
}

\author{
Laura Madalina Cursaru ${ }^{1, *(\mathbb{0})}$, Roxana Mioara Piticescu ${ }^{1, *}$, Dumitru Valentin Dragut ${ }^{1} \mathbb{D}$, \\ Ioan Albert Tudor ${ }^{1}$, Victor Kuncser ${ }^{2}$, Nicusor Iacob ${ }^{2}$ and Florentin Stoiciu ${ }^{1}$ \\ 1 National R\&D Institute for Non-Ferrous and Rare Metals, INCDMNR-IMNR, 102 Biruintei blvd, Pantelimon, \\ 077145 Ilfov, Romania; dragutv@imnr.ro (D.V.D.); atudor@imnr.ro (I.A.T.); fstoiciu@imnr.ro (F.S.) \\ 2 National Institute of Materials Physics, Atomistilor 105bis, P.O. Box MG-7, 077125 Bucharest-Magurele, \\ Romania; kuncser@infim.ro (V.K.); nicusor.iacob@infim.ro (N.I.) \\ * Correspondence: roxana.piticescu@imnr.ro (R.M.P.); mpopescu@imnr.ro (L.M.C.); \\ Tel.: +40-21-352-2048 (R.M.P.); +40-21-352-2048 (L.M.C.)
}

Received: 2 December 2019; Accepted: 23 December 2019; Published: 2 January 2020

check for updates

\begin{abstract}
Magnetic iron oxides have been used in biomedical applications, such as contrast agents for magnetic resonance imaging, carriers for controlled drug delivery and immunoassays, or magnetic hyperthermia for the past 40 years. Our aim is to investigate the effect of pressure and temperature on the structural, thermal, and magnetic properties of iron oxides prepared by hydrothermal synthesis at temperatures of $100-200{ }^{\circ} \mathrm{C}$ and pressures of 20-1000 bar. It has been found that pressure influences the type of iron oxide crystalline phase. Thus, the results obtained by Mössbauer characterization are in excellent agreement with X-ray diffraction and optical microscopy characterization, showing that, for lower pressure values ( $<100 \mathrm{bar}$ ), hematite is formed, while, at pressures $>100$ bar, the major crystalline phase is goethite. In addition, thermal analysis results are consistent with particle size analysis by X-ray diffraction, confirming the crystallization of the synthesized iron oxides. One order of magnitude higher magnetization has been obtained for sample synthesized at 1000 bar. The same sample provides after annealing treatment, the highest amount of good quality magnetite leading to a magnetization at saturation of $30 \mathrm{emu} / \mathrm{g}$ and a coercive field of 1000 Oe at $10 \mathrm{~K}$ and 450 Oe at $300 \mathrm{~K}$, convenient for various applications.
\end{abstract}

Keywords: iron oxide nanoparticles; hydrothermal synthesis; high pressure; magnetic properties; thermal stability

\section{Introduction}

Magnetic iron oxide particles have been used for in vitro diagnostics for the past 40 years. Due to the unique physical, chemical, thermal and mechanical properties of iron oxide nanoparticles, as well as their biocompatibility and low toxicity in the human body, they have been used in many biomedical applications [1-6], such as contrast agents [7] for magnetic resonance imaging (MRI), carriers for controlled drug delivery and immunoassays [8-13], and also in magnetic hyperthermia [14-23]. All these applications require the particles to be superparamagnetic at room temperature. Aggregation of nanoparticles should be avoided to prevent blockage of blood vessels. In addition, the particles' stability in water at neutral $\mathrm{pH}$ is very important for these applications and the colloidal stability of the magnetic fluid depends on the coating materials and the particle size [24,25]. Magnetic iron oxide nanoparticles with polymer coatings have also been used in cell separation, protein purification and organic or biochemical syntheses [26-30]. Coatings are not only used to enhance stability, but also particle functionality. On the other hand, it is known that when the size of the magnetic material is close to or smaller than the size of the characteristic parameters, the effect of small particle sizes 
can influence the important physical properties of nanostructures, such as structural phase transition temperature or Néel temperature (the temperature at which an anti-ferromagnetic material becomes paramagnetic). For example, Jiang's group found that changing the size and grain size of metal and alloy can alter the phase transition temperature [31].

Ruan et al. [31] studied the thermal stability of nano-rings and nanotubes of $\alpha-\mathrm{Fe}_{2} \mathrm{O}_{3}$ and found that it is closely related to the surface fraction of (001) plane in nanostructures. It has also been found that the different thickness of $\alpha-\mathrm{Fe}_{2} \mathrm{O}_{3}$ nano-rings may affect their thermal stability. Recently, numerous experimental studies have been conducted to investigate the size effect on phase transitions [31-38]. The stability of hematite $\left(\alpha-\mathrm{Fe}_{2} \mathrm{O}_{3}\right)$ of various morphologies has also been studied.

Most papers focused on oxidation from $\mathrm{Fe}_{3} \mathrm{O}_{4}$ to $\alpha-\mathrm{Fe}_{2} \mathrm{O}_{3}$ or $\gamma-\mathrm{Fe}_{2} \mathrm{O}_{3}$ to $\alpha-\mathrm{Fe}_{2} \mathrm{O}_{3}$, as these phase changes are found to be associated with particle size, nanostructure, and other factors. The quasi-cubic phase stability of $\alpha-\mathrm{Fe}_{2} \mathrm{O}_{3}$ was studied using magnetic measurements at high temperatures in high vacuum. The results showed that phase transformation from $\alpha-\mathrm{Fe}_{2} \mathrm{O}_{3}$ (low ferromagnetic hematite) to $\mathrm{Fe}_{3} \mathrm{O}_{4}$ (ferrimagnetic magnetite) strongly depends on the size of the structures. $\mathrm{Fe}_{2} \mathrm{O}_{3}$ presents a defined chemical phase $\left(\mathrm{Fe}^{3+}\right)$ with high chemical stability, while the mixed chemical state of $\mathrm{Fe}_{3} \mathrm{O}_{4}$ $\left(\mathrm{Fe}^{2+}{ }^{3+}\right)$ could induce instability [39].

The spectroscopic and morphological characterization of $\mathrm{Fe}_{2} \mathrm{O}_{3}$ nanowires (NWs) was performed according to calcination temperature to assess the thermal stability of NWs and temperatures over which a chemical reduction of Fe ions occurred. Thermogravimetric measurements clearly show the reduction in mass due to oxygen loss, while infrared and photoemission measurements allow tracking of the reduction of iron ions at different temperatures, indicating chemical reduction to $\mathrm{Fe}_{3} \mathrm{O}_{4}$ starting at moderate temperatures (above $440 \mathrm{~K}$ ).

According to literature data, magnetite nanomaterials are very vulnerable to oxidation in air at temperatures above $150^{\circ} \mathrm{C}$. During heating in the presence of oxygen, magnetite nanoparticles are transformed into maghemite and then into hematite. A similar effect of magnetite oxidation can be induced by laser irradiation [40,41]. At a macroscopic level, oxidation of magnetite to hematite at room temperature is inhibited and changes in the crystalline structure can be achieved only by heating at $600{ }^{\circ} \mathrm{C}$. At the nanometric level, changes in crystalline structure can be expected and observed at much lower temperatures even close to room temperature. This is due to enthalpy and activation energy, which depend on particle size.

It was found that Fe nanoparticles are oxidized to a mixture of iron oxides $\left(\gamma-\mathrm{Fe}_{2} \mathrm{O}_{3}\right.$ and $\left.\alpha-\mathrm{Fe}_{2} \mathrm{O}_{3}\right)$ even at $200{ }^{\circ} \mathrm{C}$. However, this temperature may vary due to the large surface area and the various activities of the nanoparticles, which leads to a higher exothermic process during low temperature oxidation. In general, it can be assumed that phase transformations in nano-granular systems occur from $200{ }^{\circ} \mathrm{C}$ to $600{ }^{\circ} \mathrm{C}$ with different contributions of oxides, $\gamma-\mathrm{Fe}_{2} \mathrm{O}_{3}$, and $\alpha-\mathrm{Fe}_{2} \mathrm{O}_{3}$. It should also be emphasized that data on the behavior of nanosystems in high-temperature conditions are very different and generalizations cannot be made [42].

To our knowledge, there have been no investigations regarding the effect of high pressure on the formation and phase transformations of iron oxides in aqueous environments under hydrothermal conditions. In our previous work [43], the influence of the main synthesis parameters (temperature, time, pressure) on the formation of nanosized $\mathrm{Fe}_{2} \mathrm{O}_{3}$ particles has been studied up to the pressure of 20 bar.

In the present study, our aim is to investigate the effect of pressure (up to 1000 bar) and temperature, as main hydrothermal synthesis parameters on the formation of different crystalline phases of nanostructured iron oxides and on structural, thermal, and magnetic properties of iron oxide nanomaterials. 


\section{Materials and Methods}

\subsection{Hydrothermal Synthesis of Hematite}

$\mathrm{FeCl}_{3} \cdot 6 \mathrm{H}_{2} \mathrm{O}$, p.a, 99\% (Merck KGaA, Darmstadt, Germany), and ammonia solution (Chimreactiv SRL, Bucharest, Romania) were used for hydrothermal synthesis of iron oxides.

In a first step, $\mathrm{FeCl}_{3} \cdot 6 \mathrm{H}_{2} \mathrm{O}$ was dissolved in distilled water to obtain a solution whose iron concentration was determined by the Inductively coupled Plasma-Optical Emission Spectroscopy (ICP-OES) method. For the precipitation of the iron oxide precursors, a $25 \%$ ammonia solution was added dropwise under magnetic stirring. A brown precipitate with alkaline $\mathrm{pH}$ was obtained. Thus, obtained suspension was washed with water to remove the by-products.

In the second step, the washed suspension (iron oxide precursor) was transferred to the autoclave and subjected to hydrothermal synthesis at $200{ }^{\circ} \mathrm{C}$ for $3 \mathrm{~h}$. SAM autoclave (Romania) endorsed with cooling system, was used to prepare samples at pressures of 20-100 bar (experimental conditions: working volume $0.3 \mathrm{~L}$; pressure created inside the stainless steel vessel of the autoclave using argon gas; temperature $200^{\circ} \mathrm{C}$ ), while HP Systems autoclave (Bordeaux, France) was used in the case of sample obtained at 1000 bar (experimental conditions: working volume $1 \mathrm{~L}$; isostatic pressure; temperature $100{ }^{\circ} \mathrm{C}$ ). After hydrothermal treatment, the nanostructured powders were dried by lyophilization using a Martin Christ Alpha 1-2 LD Plus freeze dryer (City, US State abbrev. if applicable, Country). Experimental parameters of the investigated samples and chemical analysis results are presented in Table 1. Fe content was determined using a chemical quantitative method, according to STAS 1574/3-90.

Table 1. Synthesis conditions of iron oxide nanostructures prepared in this work and Fe content of the investigated samples, according to quantitative chemical analysis.

\begin{tabular}{cccc}
\hline Sample Name & Synthesis Conditions & Material Structure & Fe, wt $\%$ \\
\hline NV4 & $200{ }^{\circ} \mathrm{C} / 3 \mathrm{~h} / 20 \mathrm{bar}$ & hematite & 68.87 \\
\hline NV5 & $200^{\circ} \mathrm{C} / 3 \mathrm{~h} / 60 \mathrm{bar}$ & hematite & 68.41 \\
\hline NV6 & $200^{\circ} \mathrm{C} / 3 \mathrm{~h} / 100 \mathrm{bar}$ & hematite & 68.32 \\
\hline NV7 & $100^{\circ} \mathrm{C} / 3 \mathrm{~h} / 1000 \mathrm{bar}$ & hematite/goethite & 61.74 \\
\hline
\end{tabular}

\subsection{Characterization Methods}

The crystal structure and the phases present in the synthesized nanopowders were analyzed using X-ray phase analysis. X-ray diffraction (XRD) patterns were obtained by Bruker-AXS D8 ADVANCE diffractometer (Bruker AXS GmbH, Karlsruhe, Germany) equipped with CuK $\alpha$ radiation source and a scintillation detector with graphite monochromator in vertical geometry $\theta-\theta$. XRD patterns were recorded in the range of $2 \theta=14-84^{\circ}$ at the scan speed of 0.02 degrees/s, using DIFFRAC.EVA version 2016 software (Bruker AXS GmbH, Karlsruhe, Germany) and the ICDD PDF 4+ 2019 database. The chemical structure of the synthesized products was determined by Fourier Transform Infrared spectroscopy (FT-IR) within the scanning range of $550-4000 \mathrm{~cm}^{-1}$ in transmittance mode. Measurements were performed using a FT-IR ABB MB 3000 spectrometer (ABB Inc., Québec, QC, Canada) equipped with a Diffuse reflection accessory, EasiDiff device (PIKE Technologies, Inc., Madison, WI, USA) for qualitative powder analysis. The solid sample was mixed with $\mathrm{KBr}$ powder so that its concentration in the mixture was $1 \mathrm{wt} \%$. The mixture thus obtained is milled for $15 \mathrm{~min}$ to grind grains and obtain fine, homogeneous particles. For data acquisition, 64 scans were made at an optical resolution of $4 \mathrm{~cm}^{-1}$. Experimental data processing was performed with the help of the FTIR software Horizon MB version 3.4.0.3 (ABB Inc., Québec, QC, Canada). A CARL ZEISS Axio Imager A1m microscope (Carl Zeiss Microimaging Gmbh, Göttingen, Germany), with polarized, transmitted and reflected light, equipped with digital camera for image acquisition and AxioVision Release 4.8.1 software for image processing, was employed to explore the morphology and to determine the microcrystalline phases based on color differences. For the microscopic study, the samples were embedded in EpoThin-Buehler 
resin, sanded on abrasive paper and polished onto a Lecloth-type cloth, soaked in a suspension of $\alpha$-alumina in water and immersed in cedar oil. The illumination source was 100 HAL lamp of the optical microscope. The image was captured with a Canon Power Shot A 640 digital camera (Melville, NY, USA), $4 \times$ digital zoom. Morphology and semi-quantitative analysis of iron oxide nanopowders was further investigated using scanning electron microscopy (SEM) coupled with Energy-dispersive X-ray analysis (EDS). SEM/EDS characterization was performed with a Quanta 250 scanning electron microscope (FEI, Eindhoven, Netherlands) of high resolution, fully digitized, and an Energy-dispersive X-Ray spectrometer consisting of ELEMENT Silicon Drift Fixed Detector, and ELEMENT EDS Analysis Software Suite, manufactured by EDAX (Draper, UT, USA). The samples were coated by gold to gain better conductivity required for high quality SEM imaging. Differential Scanning Calorimetry (DSC) was performed using a NETZSCH DSC 200 F3 Maia differential scanning calorimeter (NETZSCH-Gerätebau GmbH, Selb, Germany) in Ar atmosphere worked in Al crucibles up to $590{ }^{\circ} \mathrm{C}$, with a heating rate of $10 \mathrm{~K} / \mathrm{min}$ and cooling of $30 \mathrm{~K} / \mathrm{min}$. The processing of the experimental data was done with the help of the thermal analysis software PROTEUS 7.0 (NETZSCH-Gerätebau GmbH, Selb, Germany).

Differential Scanning Calorimetry coupled with thermogravimetry (DSC-TG) was performed with the Setaram Setsys Evolution apparatus (Setaram Instrumentation, Caluire, France) under inert gas atmosphere $(\mathrm{Ar} / \mathrm{He})$, alumina crucibles, with heating rates of $10-50^{\circ} / \mathrm{min}$, from room temperature to $1000^{\circ} \mathrm{C}$, then 5 heating-cooling cycles up to $800{ }^{\circ} \mathrm{C}$ at $30^{\circ} / \mathrm{min}$ (for NV5, NV7 samples) and $20^{\circ} / \mathrm{min}$ respectively (for NV4 and NV6 samples). Thermal Analysis Software Calisto v1.097 (by Setaram Instrumentation, Caluire, France) was used to process the experimental data.

The magnetic measurements have been performed by SQUID (Superconducting Quantum Interference Device) magnetometry. The MPMS 7T (Quantum Design, San Diego, CA, USA) machine was used, as working under the most sensitive Reciprocal Space Option [44]. ZFC-FC (Zero Field Cooled-Field Cooled) measurements under an applied field of $80 \mathrm{Oe}$ ( $0.008 \mathrm{~T}$ magnetic field induction) have been performed in the temperature interval from $10 \mathrm{~K}$ to $300 \mathrm{~K}$. This procedure consists of cooling down a system of nanoparticles from the superparamagnetic state to the magnetic frozen state in the absence of any applied magnetic field. The magnetization of the sample is further measured in an applied low magnetic field (e.g. the measuring field of 80 Oe in this case), at increasing temperature up to the superparamagnetic regime. This measured curve is called the ZFC curve because it was obtained after a zero field cooling procedure (see energy implications in [45]). Further on, the sample is again cooled down, this time in an applied magnetic field (usually the measuring field) down to the initial lowest temperature and measured again (e.g., in the same measuring field) at increasing temperature up to the superparamagnetic regime (FC curve). While the FC curve is reversible, it can be measured directly in the same measuring field by decreasing temperature from the superparamagnetic state, just after completing the ZFC curve. In addition, magnetic hysteresis loops have been collected on the investigated samples at $10 \mathrm{~K}$ and $300 \mathrm{~K}$.

The Fe phase composition and local spin structure have been investigated by 57Fe Mössbauer spectroscopy using a constant acceleration spectrometer from SEECo, Edina, MN, USA. Mössbauer spectra at $295 \mathrm{~K}$ and $6 \mathrm{~K}$ have been acquired by inserting the sample in a close cycle cryostat (JANIS, Woburn, MA, USA). The isomer shifts are reported relative to $\alpha$-Fe.

\section{Results and Discussion}

\subsection{X-Ray Diffraction (XRD) Characterization}

The main crystalline phases identified in the iron oxide powders obtained by the hydrothermal process as well as their crystallite size are described in Table 2. 
Table 2. Crystallite size (calculated using Scherrer formula) and crystalline phases of hydrothermally synthesized iron oxide nanostructures (NVx), determined by X-ray diffraction (XRD), according to the reference patterns in the International Centre for Diffraction Data Powder Diffraction File (ICDD PDF) $4+2019$ database.

\begin{tabular}{ccccc}
\hline Sample & $\begin{array}{c}\text { Crystallite Size } \\
\text { (Scherrer), } \mathbf{n m}\end{array}$ & $\begin{array}{c}\text { The Crystalline Phase } \\
\text { Identified by XRD; Phase } \\
\text { Content * }\end{array}$ & Formula & PDF References \\
\hline NV4 & 36 & $100 \%$ Hematite & $\mathrm{Fe}_{2} \mathrm{O}_{3}$ & $01-089-0599$ \\
\hline NV5 & 32 & $100 \%$ Hematite & $\mathrm{Fe}_{2} \mathrm{O}_{3}$ & $01-089-0599$ \\
\hline \multirow{2}{*}{ NV6 } & 37 & $96.7 \%$ Hematite & $\mathrm{Fe}_{2} \mathrm{O}_{3}$ & $01-089-0599$ \\
& 22 & $3.3 \%$ Goethite & $\mathrm{FeO}(\mathrm{OH})_{01-081-0464(\mathrm{I})}$ \\
\hline \multirow{2}{*}{ NV7 } & 33 & $\sim 66 \%$ Hematite & $\mathrm{Fe}_{2} \mathrm{O}_{3}$ & $01-077-9924\left(^{*}\right)$ \\
& 25 & $\sim 34 \%$ Goethite & $\mathrm{FeO}(\mathrm{OH})$ & $00-029-0713(\mathrm{I})$ \\
\hline
\end{tabular}

* It should be noted that the percentage of crystalline phases calculated from XRD is a semi-quantitative estimation.

Figure 1 presents the XRD patterns of the investigated samples.

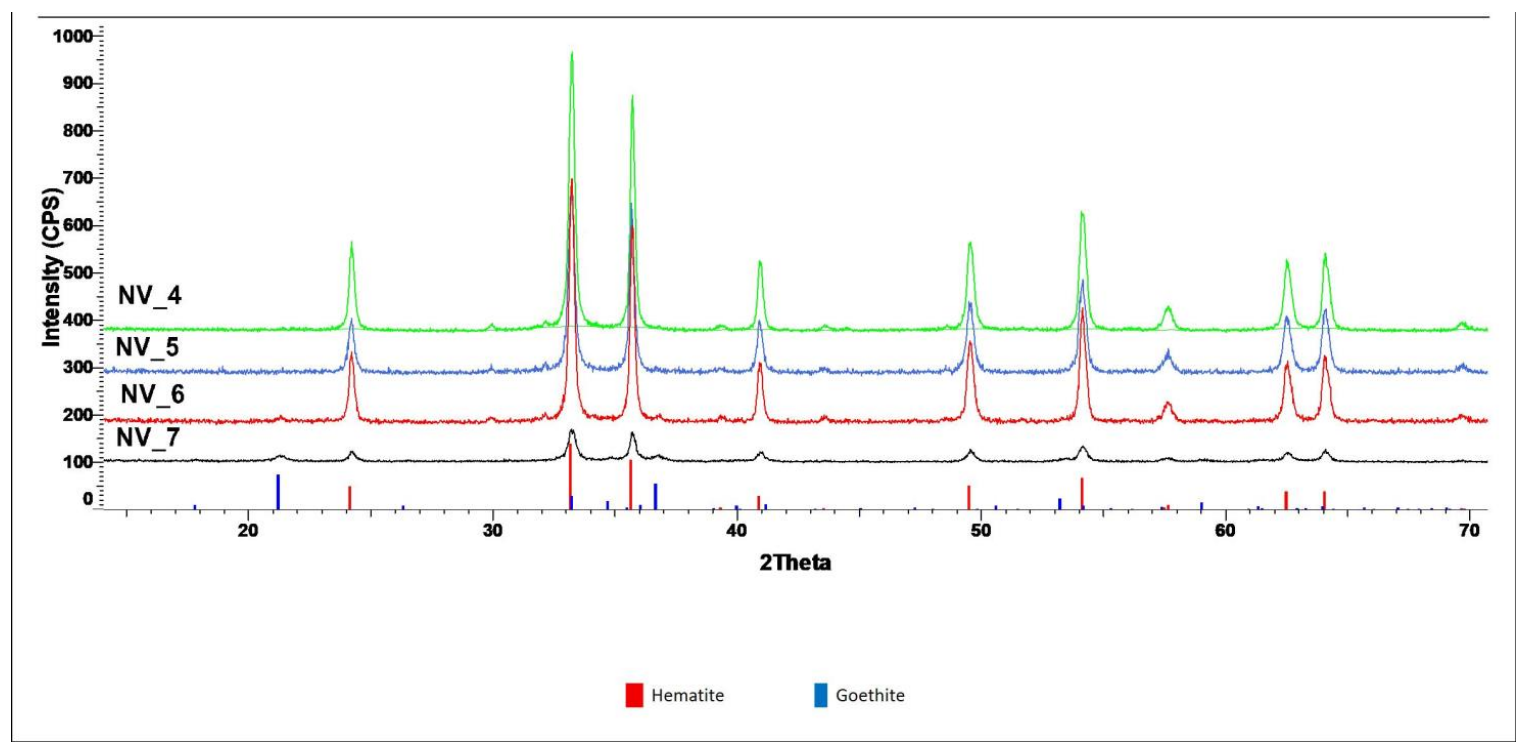

Figure 1. X-ray diffraction (XRD) patterns of samples NV4, NV5, NV6, and NV7, compared to the XRD patterns of hematite (red) and goethite (blue) from the International Centre for Diffraction Data Powder Diffraction File (ICDD PDF) 4+ 2019 data base.

X-ray diffraction highlights the formation of hematite as the major crystalline phase in all samples synthesized by the hydrothermal process.

The main characteristic peaks of hematite $\left(\mathrm{Fe}_{2} \mathrm{O}_{3}\right)$ were identified at $2 \theta=33.165^{\circ}$, which corresponds to the (104) diffraction plane and at $2 \theta=35.608^{\circ}$, corresponding to the (110) diffraction plane. The small peak visible at $2 \theta=21.24^{\circ}$ is attributed to the goethite structure, $\mathrm{FeO}(\mathrm{OH})$ structure corresponding to the (110) plane.

The crystallite sizes presented in Table 2 were calculated using Scherrer formula and the values represent the sizes on the (104)-growth direction (hematite) and (110) growth direction (goethite). It is worth noting that, in the case of NV6 sample, synthesized at a pressure of $100 \mathrm{~atm}$, it is observed that formation of goethite as the secondary phase $(\sim 3 \%)$, probably due to higher working pressure compared to NV4 samples (20 atm) and NV5 (60 atm). It can be observed that the formation of $\mathrm{FeO}(\mathrm{OH})$ structure as a secondary phase is favored by pressure $[46,47]$. In addition, its crystallite size tends to increase with increasing pressure, while the crystallite size of the $\mathrm{Fe}_{2} \mathrm{O}_{3}$ tends to decrease. 


\subsection{FT-IR Analysis}

FT-IR analysis of iron oxide based powders is depicted in Figure 2.

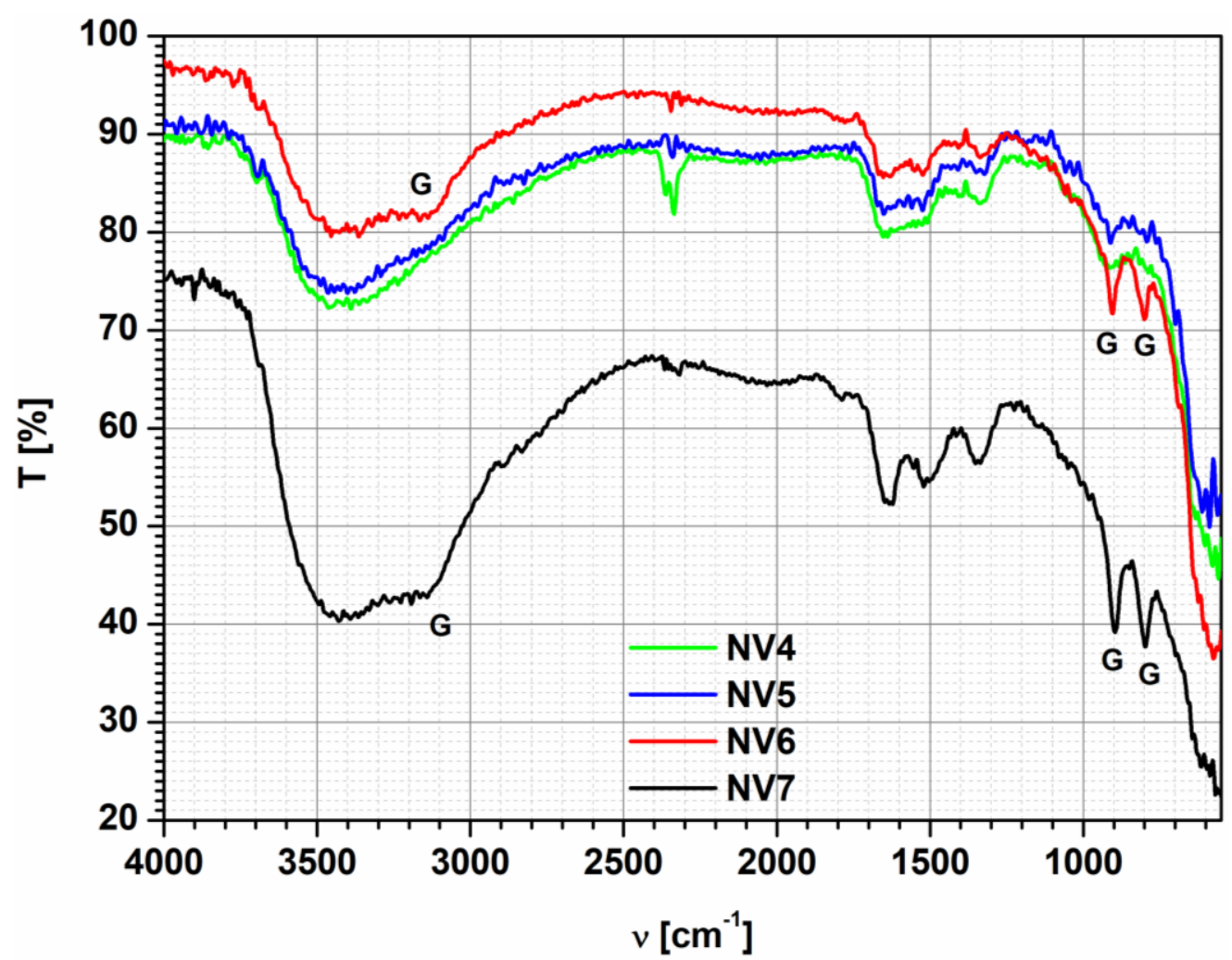

Figure 2. Fourier transform infrared (FT-IR) spectra of iron oxide samples synthesized in hydrothermal conditions at high pressure: NV4 (20 bar), NV5 (60 bar), NV6 (100 bar), and NV7 (1000 bar).

In the samples NV6 and NV7, the presence of the following vibration bands specific for goethite, and marked with G in Figure 4, was revealed: 905 and $800 \mathrm{~cm}^{-1}$ in the NV6 sample, respectively, 897 and $797 \mathrm{~cm}^{-1}$ in the NV7 sample. In addition, the stretching vibration of the O-H group at $3123 \mathrm{~cm}^{-1}$ in the sample NV6 and $3140 \mathrm{~cm}^{-1}$ in the sample NV7 is attributed to goethite, according to Betancur et al. [48]. In all the samples, one can see stretching vibration bands of the $\mathrm{OH}$ groups in the range $3600-3200 \mathrm{~cm}^{-1}$, located on the surface of the iron oxides [8]. In addition, the peaks corresponding to the deformation vibrations of the OH groups $\left(1653 \mathrm{~cm}^{-1}\right.$ for sample NV4, $1693 \mathrm{~cm}^{-1}$ for sample NV5, $1668 \mathrm{~cm}^{-1}$ for sample NV6 and $1649 \mathrm{~cm}^{-1}$ for sample NV7) are revealed. The stretching vibration of the $\mathrm{OH}$ group specific to the hematite structure at $3362 \mathrm{~cm}^{-1}$ in the NV6 sample confirms the results obtained by XRD analysis according to which this sample is a mixture of hematite and goethite. In addition, the characteristic bands of Goethite in the NV7 sample confirm the hypothesis formulated based on the UV-VIS results, NV7 having a crystalline structure predominantly composed of goethite. The bands in the range 1335-1524 $\mathrm{cm}^{-1}$ observed especially in the samples NV4, NV6, and NV7 are probably due to carbonation of the powders, the band at $1335 \mathrm{~cm}^{-1}$ being assigned to the $\left(\mathrm{HCO}_{3}\right)^{-}$ group and the band at $1524 \mathrm{~cm}^{-1}$ to the group of $\left(\mathrm{CO}_{3}\right)^{2-}$ [49]. Specific Fe-O hematite vibration occurs in NV4 sample at $646 \mathrm{~cm}^{-1}$ and NV7 at $644 \mathrm{~cm}^{-1}$, respectively.

\subsection{Optical Microscopy Characterization (OM)}

As one can observe in Figure 3, the samples consist of aggregates made of microcrystalline material, hematite $\alpha-\mathrm{Fe}_{2} \mathrm{O}_{3}$, and possible iron oxy-hydroxides such as goethite $\alpha-\mathrm{FeO}(\mathrm{OH})$. Sample NV4 consists mainly of hematite, represented by the red areas in Figure 3a, while the goethite is present in very small quantity, being represented by the gray areas on the edge. In accordance with XRD 
results, the presence of goethite (gray areas) can be observed in the case of sample NV6 next to white granules of hematite. The white color of hematite is explained by formation of larger-sized particles. The characteristic blood-red color of the hematite is specific to small granules and can be observed in the case of NV7 sample. The more abundant internal reflection is due to both phases (hematite and goethite). Less abundant internal reflexes can be observed in sample NV5. Particle granulation may be higher. Color effects may also be due to anisotropy [50-53].

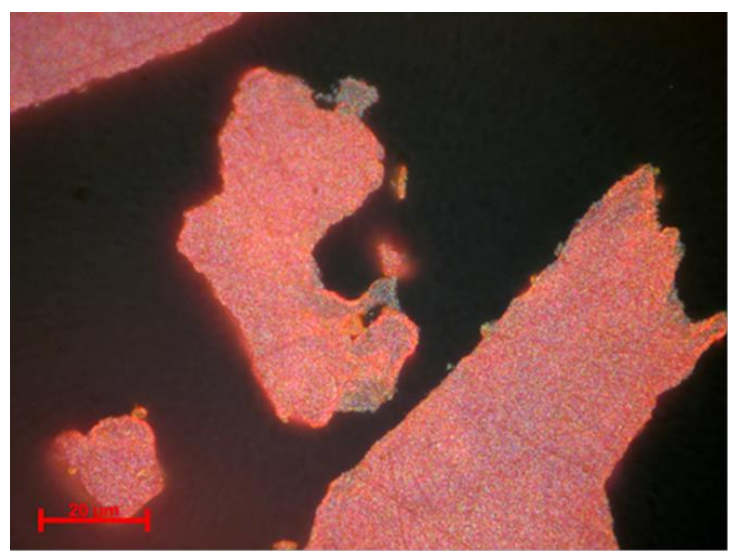

(a)

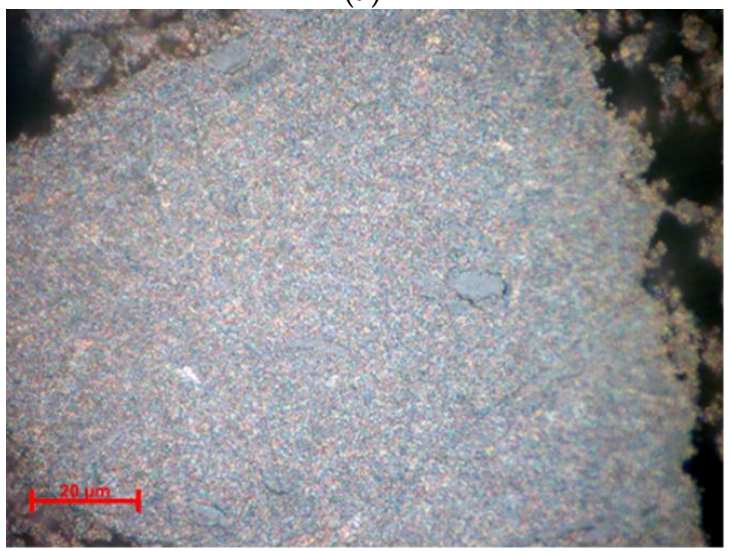

(c)

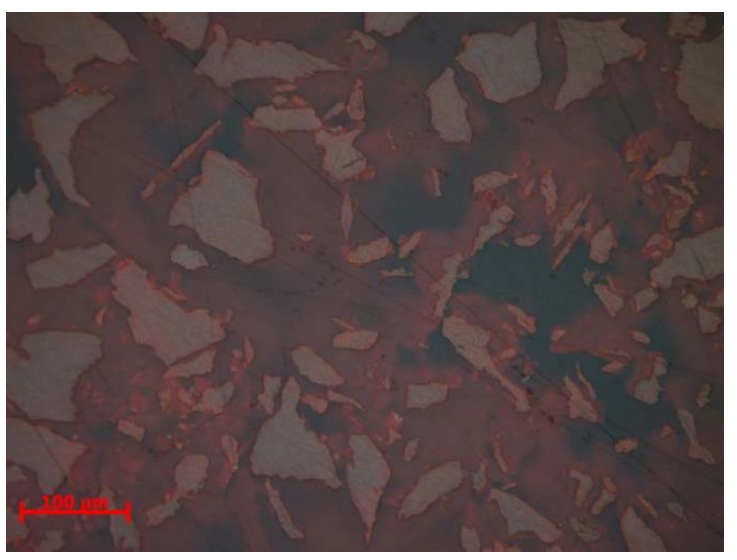

(b)

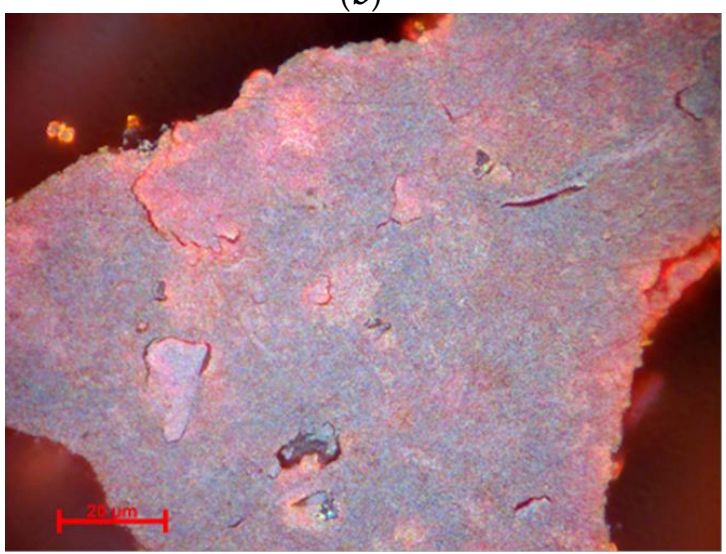

(d)

Figure 3. Reflected light, crossed Nicols, immersion in cedar oil. Microcrystalline aggregates in the sample: (a) NV4-Hematite (white, red internal reflections), magnetite (gray); (b) NV5-Hematite (white, red internal reflections), magnetite (gray); (c) NV6-Magnetite (gray), hematite (white, red internal reflections); (d) NV7-Hematite (white, red internal reflections), magnetite (gray).

\subsection{SEM-EDS Characterization}

The existence of hematite as major phase in hydrothermally synthesized samples is also demonstrated by SEM-EDS characterization, whereas goethite may appear as a secondary phase. An example of phase distribution inside NV4 sample is shown in Figure 4.

In Figure $4 \mathrm{a}$, goethite phase is represented by some small light gray areas inside hematite.

Figure $4 \mathrm{~b}$, $\mathrm{d}$ show the distribution of $\mathrm{O}$ and Fe content along the line starting from the hematite predominant area $(\mathrm{H})$ to a small goethite area $(\mathrm{G})$. It can be seen that both oxygen and iron content are relatively constant, suggesting that NV4 sample consists of almost $100 \%$ hematite, as resulted from XRD characterization. 


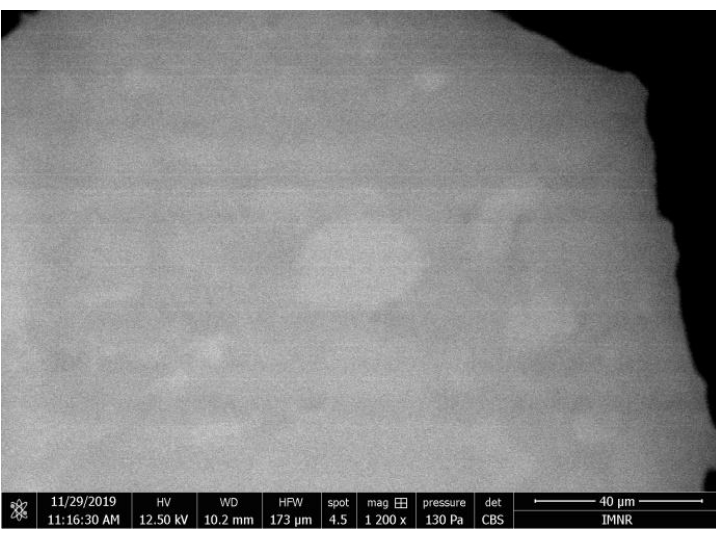

(a)

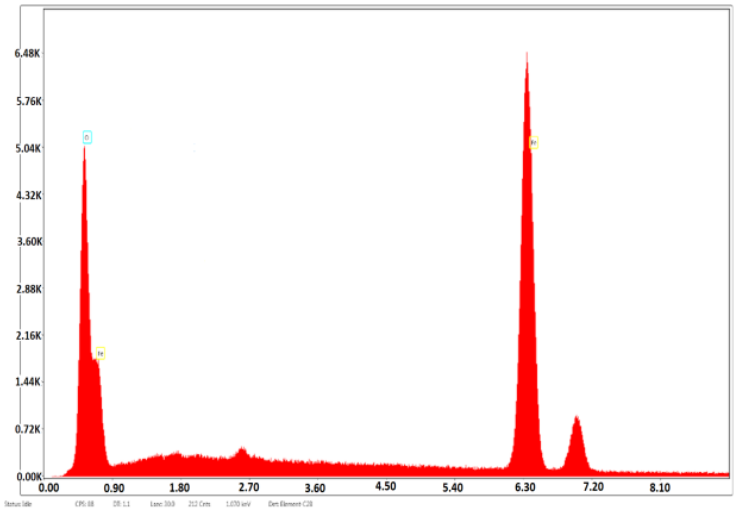

(c)

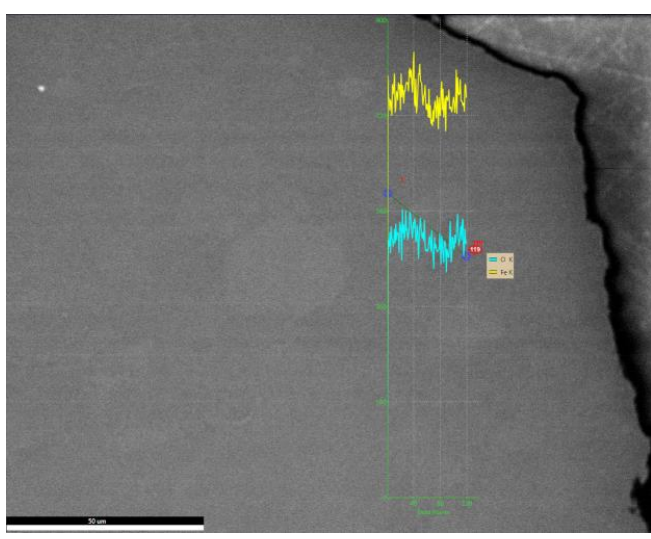

(b)

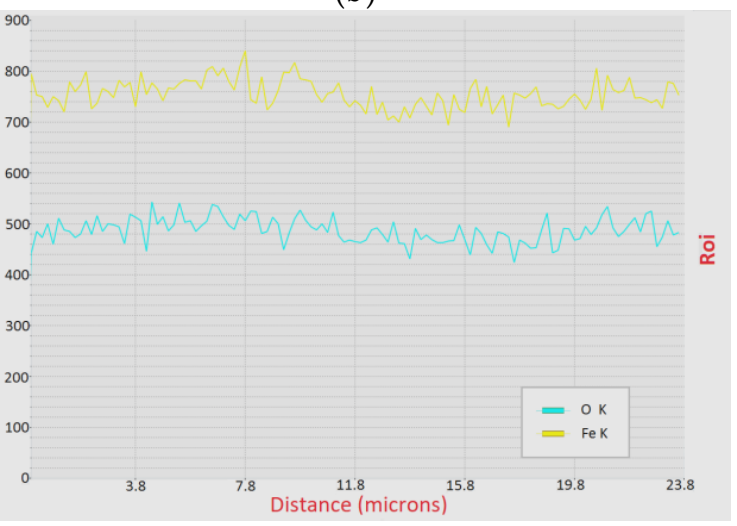

(d)

Figure 4. Scanning Electron Microscopy with Energy Dispersive Spectroscopy (SEM-EDS) characterization of a hematite sample (NV4) prepared by hydrothermal synthesis at 20 bar, embedded in EpoThin-Buehler resin: (a) micrograph by scanning electron microscopy (SEM)collected using Circular Backscatter Detector (CBS); magnification 1200x; scale bar $40 \mu \mathrm{m}$; (b) line between hematite and goethite areas; (c) elemental analysis by energy dispersive X-ray spectroscopy (EDS); (d) distribution of O (turquoise) and Fe (yellow) content along the line between hematite and goethite areas from left to right.

\subsection{DSC Analysis}

The results of the differential scanning calorimetry (DSC) analysis are shown schematically in Table 3.

Table 3. Thermal analysis results obtained by Differential Scanning Calorimetry (DSC) for iron oxide nanostructures (NVx) synthesized by hydrothermal process. Main characteristics of endothermic and exothermic peaks (temperature and enthalpy values) observed from room temperature (RT) up to 590 ${ }^{\circ} \mathrm{C}$.

\begin{tabular}{|c|c|c|c|c|c|c|c|c|c|c|}
\hline \multirow{2}{*}{ Sample } & \multicolumn{2}{|c|}{ Peak 1} & \multicolumn{2}{|c|}{ Peak 2} & \multicolumn{2}{|c|}{ Peak 3} & \multicolumn{2}{|c|}{ Peak 4} & \multicolumn{2}{|c|}{ Peak 5} \\
\hline & $\mathrm{T},{ }^{\circ} \mathrm{C}$ & $\Delta \mathrm{H}, \mathrm{J} / \mathrm{g}$ & $\mathrm{T},{ }^{\circ} \mathrm{C}$ & $\Delta \mathrm{H}, \mathrm{J} / \mathrm{g}$ & $\mathrm{T},{ }^{\circ} \mathrm{C}$ & $\Delta \mathrm{H}, \mathrm{J} / \mathrm{g}$ & $\mathrm{T},{ }^{\circ} \mathrm{C}$ & $\Delta \mathrm{H}, \mathrm{J} / \mathrm{g}$ & $\mathrm{T},{ }^{\circ} \mathrm{C}$ & $\Delta \mathrm{H}, \mathrm{J} / \mathrm{g}$ \\
\hline NV4 & 39.7 & 2.4 & 148.6 & 0.97 & 308.7 & -10.7 & & & 478.9 & -4.56 \\
\hline NV5 & 40.7 & 2.05 & 67.1 & 1.6 & 292.4 & -0.88 & 366.2 & -1.13 & 441.8 & -1.33 \\
\hline NV6 & 84.5 & 1.65 & & & 231.2 & -0.64 & 338.9 & -3.32 & & \\
\hline NV7 & 100.6 & 82.86 & 241.1 & 9.06 & 296 & 5.21 & & & 413.1 & -21.47 \\
\hline
\end{tabular}

Endothermic peaks in the range of $39.7-100.6^{\circ} \mathrm{C}$ are due to water desorption, while endothermic peaks at $148.6^{\circ} \mathrm{C}$ (sample NV4) and $241.1^{\circ} \mathrm{C}$ (sample NV7) are due to dehydration of the powder. Another endothermic peak observed in sample NV7 at $296^{\circ} \mathrm{C}$ could be attributed to decomposition 
of goethite into hematite. The exothermic peak at $231.2{ }^{\circ} \mathrm{C}$ corresponding to the NV6 sample could be explained by the removal of structural water adsorbed physically on the surface of the oxide. Exothermic peaks ranging from $338.9-478.9^{\circ} \mathrm{C}$ are probably due to polymorphic transformations from $\gamma-\mathrm{Fe}_{2} \mathrm{O}_{3}$ (maghemite) into $\alpha-\mathrm{Fe}_{2} \mathrm{O}_{3}$ (hematite). These transformations could take place in several steps, from 292.4 (in the case of the NV5 sample) and $308.7^{\circ} \mathrm{C}$ (in the case of the NV4 sample) because of the nanometric dimensions, knowing that the nanoparticles have a different thermal behavior compared to the classical materials. The phase transitions between 290 and $480{ }^{\circ} \mathrm{C}$ (supported by exothermic peaks) revealed that the synthesized samples (NV4-NV7) are well crystallized. The results are consistent with particle size analysis by X-ray diffraction (shown in Table 2), confirming the crystallization of the synthesized iron oxides (mainly hematite) $[47,54]$

\subsection{Complex Thermal Analysis Characterization (DSC-TG)}

The results of the DSC-TG analysis are shown schematically in Table 4.

Table 4. Results obtained by simultaneous thermal analysis: differential scanning calorimetry coupled with thermogravimetry (DSC-TG) for iron oxide nanostructures (NVx) synthesized by hydrothermal process. Five heating-cooling cycles have been performed for each sample up to $800{ }^{\circ} \mathrm{C}$.

\begin{tabular}{|c|c|c|c|c|c|c|c|c|c|c|c|}
\hline \multirow{2}{*}{ Sample } & \multirow{2}{*}{$\begin{array}{l}\text { Speed } \\
\% / \mathrm{min}\end{array}$} & \multicolumn{2}{|c|}{ Peak 1} & \multicolumn{2}{|c|}{ Peak 2} & \multicolumn{2}{|c|}{ Peak 3} & \multicolumn{2}{|c|}{ Peak 4} & \multicolumn{2}{|c|}{ Peak 5} \\
\hline & & $\mathrm{T},{ }^{\circ} \mathrm{C}$ & $\Delta \mathbf{H}, \mathrm{J} / \mathrm{g}$ & $\mathrm{T},{ }^{\circ} \mathrm{C}$ & $\Delta \mathrm{H}, \mathrm{J} / \mathrm{g}$ & $\mathrm{T},{ }^{\circ} \mathrm{C}$ & $\Delta \mathbf{H}, \mathrm{J} / \mathrm{g}$ & $\mathrm{T},{ }^{\circ} \mathrm{C}$ & $\Delta \mathbf{H}, \mathrm{J} / \mathrm{g}$ & $\mathrm{T},{ }^{\circ} \mathrm{C}$ & $\Delta \mathrm{H}, \mathrm{J} / \mathrm{g}$ \\
\hline \multirow{8}{*}{$\begin{array}{l}\text { NV4 } \\
5 \text { cycles } \\
\text { with } \\
20^{\circ} / \mathrm{min} \text { up } \\
\text { to } 800^{\circ} \mathrm{C}\end{array}$} & 10 & 57.04 & 5.96 & 291.44 & $\begin{array}{c}-9.19 \\
\text { exo }\end{array}$ & & & & & 676.29 & 0.30 \\
\hline & $\underset{\%}{\Delta \mathrm{m}}$ & -0.476 & & -0.222 & & & & & & -0.041 & -1.578 \\
\hline & 20 & & & 258.56 & $\begin{array}{c}-1.63 \\
\text { exo }\end{array}$ & & & 516.69 & $\begin{array}{c}-2.07 \\
\text { exo }\end{array}$ & 678.41 & 0.33 \\
\hline & $\underset{\%}{\Delta \mathrm{m}}$ & & & -0.131 & & & & -0.027 & & -0.044 & -1.794 \\
\hline & 30 & 91.38 & 5.86 & 320.72 & $\begin{array}{c}-2.73 \\
\text { exo }\end{array}$ & 389.34 & $\begin{array}{c}-0.13 \\
\text { exo }\end{array}$ & 449.94 & 0.39 & 677.92 & 0.30 \\
\hline & $\begin{array}{c}\Delta \mathrm{m}, \\
\%\end{array}$ & -0.59 & & -0.168 & & -0.035 & & -0.053 & & -0.036 & -1.686 \\
\hline & 50 & 84.29 & 0.27 & 339.48 & 0.28 & & & & & 679.23 & 0.38 \\
\hline & $\underset{\%}{\Delta \mathrm{m}}$ & -0.167 & & -0.101 & & & & & & -0.018 & -1.737 \\
\hline \multirow{8}{*}{$\begin{array}{c}\text { NV5 } \\
5 \text { cycles } \\
\text { with } \\
30^{\circ} / \mathrm{min} \text { up } \\
\text { to } 800^{\circ} \mathrm{C}\end{array}$} & 10 & 70.79 & 7.10 & 257.45 & 0.72 & & & & & 680.94 & 0.26 \\
\hline & $\underset{\%}{\Delta \mathrm{m}}$ & -0.395 & & -0.152 & & & & & & $\begin{array}{c}-6.25 \\
\times \\
10^{-3}\end{array}$ & -1.556 \\
\hline & 20 & 92.83 & 5.56 & 299.67 & $\begin{array}{c}-5.22 \\
\text { exo }\end{array}$ & 380.17 & $\begin{array}{c}-0.55 \\
\text { exo }\end{array}$ & 466.56 & $\begin{array}{c}-0.56 \\
\text { exo }\end{array}$ & 678.68 & 0.39 \\
\hline & $\underset{\%}{\Delta \mathrm{m}}$ & -0.537 & & -0.255 & & -0.057 & & -0.041 & & -0.043 & -1.546 \\
\hline & 30 & 106.47 & 21.87 & 273.97 & $\begin{array}{c}-1.08 \\
\text { exo }\end{array}$ & 370.96 & $\begin{array}{c}-8.15 \\
\text { exo }\end{array}$ & 512.55 & $\begin{array}{c}-1.51 \\
\text { exo }\end{array}$ & 679.26 & 0.36 \\
\hline & $\begin{array}{c}\Delta \mathrm{m}, \\
\%\end{array}$ & -0.803 & & -0.095 & & -0.32 & & -0.126 & & -0.039 & -1.751 \\
\hline & 50 & 121.51 & 17.05 & & & & & & & 680.32 & 0.58 \\
\hline & $\begin{array}{c}\Delta \mathrm{m}, \\
\%\end{array}$ & -0.686 & & & & & & & & -0.018 & -1.501 \\
\hline
\end{tabular}


Table 4. Cont

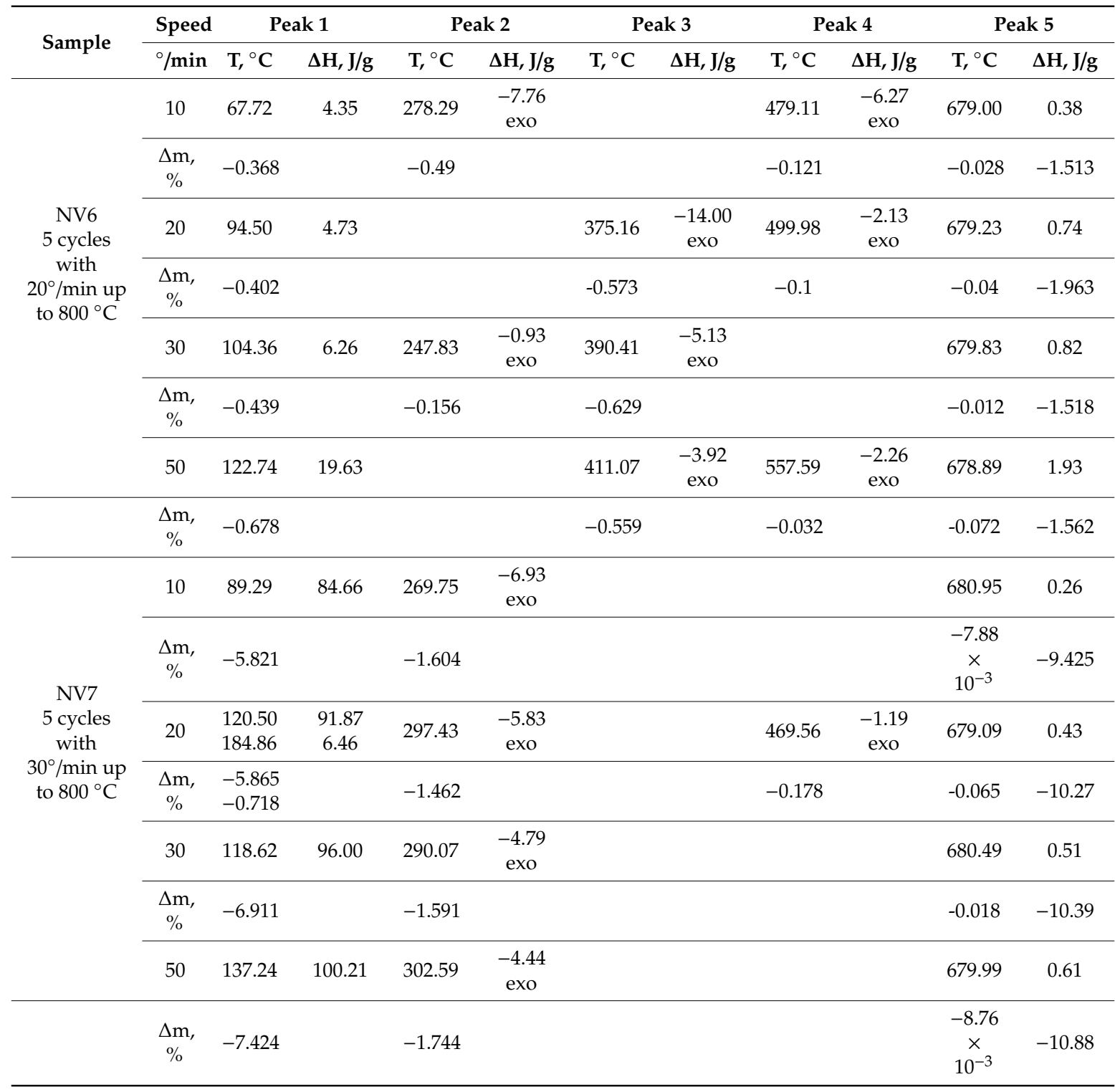

Exothermic maxima occur in temperature range $250-340{ }^{\circ} \mathrm{C}$ (probably due to secondary compounds or unreacted precursors) and $450-550{ }^{\circ} \mathrm{C}$ (probably due to polymorphic transformation $\gamma-\mathrm{Fe}_{2} \mathrm{O}_{3}$ to $\left.\alpha-\mathrm{Fe}_{2} \mathrm{O}_{3}\right)$. In addition to the endothermic maximum due to water loss $\left(57-137{ }^{\circ} \mathrm{C}\right)$, another endothermic effect occurs at $680^{\circ} \mathrm{C}$, regardless of the heating rate, representing the Curie temperature of the hematite [55]. In order to compare the crystalline phases and crystallite sizes of iron oxides before and after thermal treatment at $680{ }^{\circ} \mathrm{C}$, the resulted powders were subjected to morpho-structural characterization.

\subsection{Morpho-Structural Characterization of Thermally Treated Samples}

\subsubsection{XRD Characterization}

XRD patterns of samples after thermal treatment at $680^{\circ} \mathrm{C}$, denoted as NVx-TT, are depicted in Figure 5, while its corresponding crystallite sizes are presented in Table 5. 


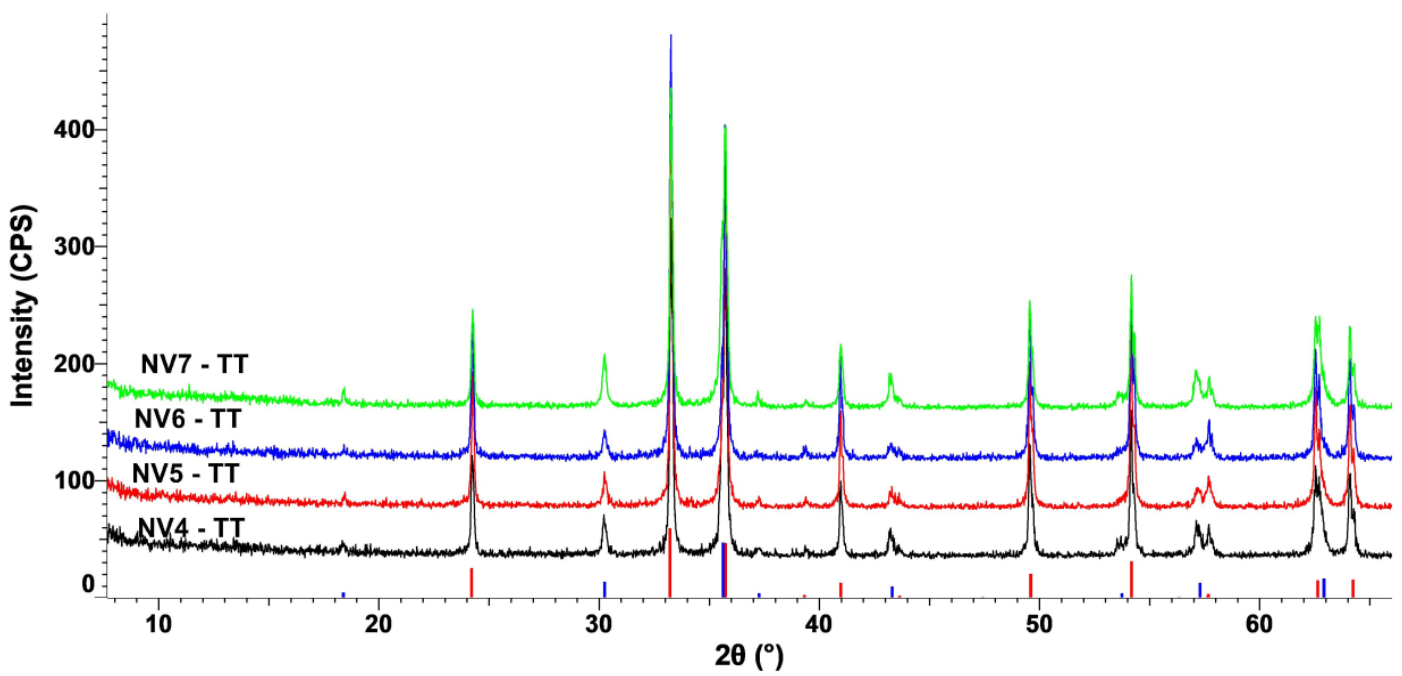

\section{H-Hematite | M-Magnetite}

Figure 5. X-ray diffraction (XRD) patterns of thermally treated samples NV4-TT, NV5-TT, NV6-TT, and NV7-TT, compared to the XRD patterns of hematite (red) and magnetite (blue) from the ICDD PDF 4+ 2019 data base.

Table 5. Crystallite size (calculated using Scherrer formula) and crystalline phases of thermally treated samples (NVx-TT), determined by X-ray difraction (XRD), according to the reference patterns in the ICDD PDF 4+ 2019 database.

\begin{tabular}{|c|c|c|c|c|c|}
\hline $\begin{array}{l}\text { Sample } \\
\text { Name }\end{array}$ & Pressure, Bar & $\begin{array}{l}\text { Crystallite Size } \\
\text { (Scherrer), nm }\end{array}$ & $\begin{array}{c}\text { The Crystalline } \\
\text { Phase Identified } \\
\text { by XRD; Phase } \\
\text { Content * }\end{array}$ & Formula & PDF References \\
\hline NV4-TT & 20 & 81.6 & $\begin{array}{l}77 \% \text { Hematite } \\
23 \% \text { Magnetite }\end{array}$ & $\begin{array}{l}\mathrm{Fe}_{2} \mathrm{O}_{3} \\
\mathrm{Fe}_{3} \mathrm{O}_{4}\end{array}$ & $\begin{array}{l}\text { PDF 04-003-5818 (P) } \\
\text { PDF 04-007-2718 }\left(^{*}\right)\end{array}$ \\
\hline NV5-TT & 60 & 93 & $\begin{array}{l}86 \% \text { Hematite } \\
14 \% \text { Magnetite }\end{array}$ & $\begin{array}{l}\mathrm{Fe}_{2} \mathrm{O}_{3} \\
\mathrm{Fe}_{3} \mathrm{O}_{4}\end{array}$ & $\begin{array}{l}\text { PDF 04-003-5818 (P) } \\
\text { PDF 04-007-2718 }\left(^{*}\right)\end{array}$ \\
\hline NV6-TT & 100 & 82.6 & $\begin{array}{l}89 \% \text { Hematite } \\
11 \% \text { Magnetite }\end{array}$ & $\begin{array}{l}\mathrm{Fe}_{2} \mathrm{O}_{3} \\
\mathrm{Fe}_{3} \mathrm{O}_{4}\end{array}$ & $\begin{array}{l}\text { PDF 04-003-5818 (P) } \\
\text { PDF 04-007-2718 }\left(^{*}\right)\end{array}$ \\
\hline NV7-TT & 1000 & 86.4 & $\begin{array}{l}72 \% \text { Magnetite } \\
28 \% \text { Hematite }\end{array}$ & $\begin{array}{l}\mathrm{Fe}_{3} \mathrm{O}_{4} \\
\mathrm{Fe}_{2} \mathrm{O}_{3}\end{array}$ & $\begin{array}{l}\text { PDF 04-007-2718 }\left(^{*}\right) \\
\text { PDF 04-003-5818 (P) }\end{array}$ \\
\hline
\end{tabular}

* It should be noted that the percentage of crystalline phases calculated from XRD is a semi-quantitative estimation.

After thermal treatment at $680^{\circ} \mathrm{C}$, the increasing of crystallite size (from 20-40 nm to 80-90 nm) and the partial transformation of hematite into magnetite can be observed.

\subsubsection{Optical Microscopy Characterization}

Optical microscopy images of the thermally treated samples (NVx-TT) are presented in Figure 6. 


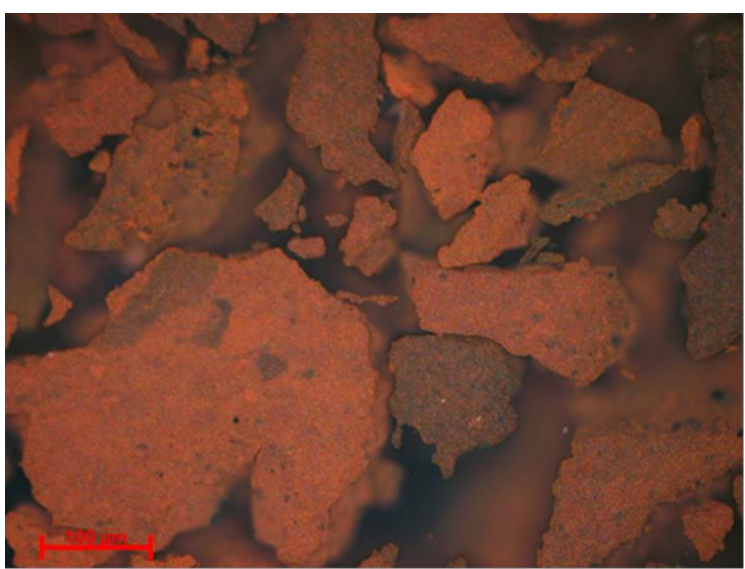

(a)

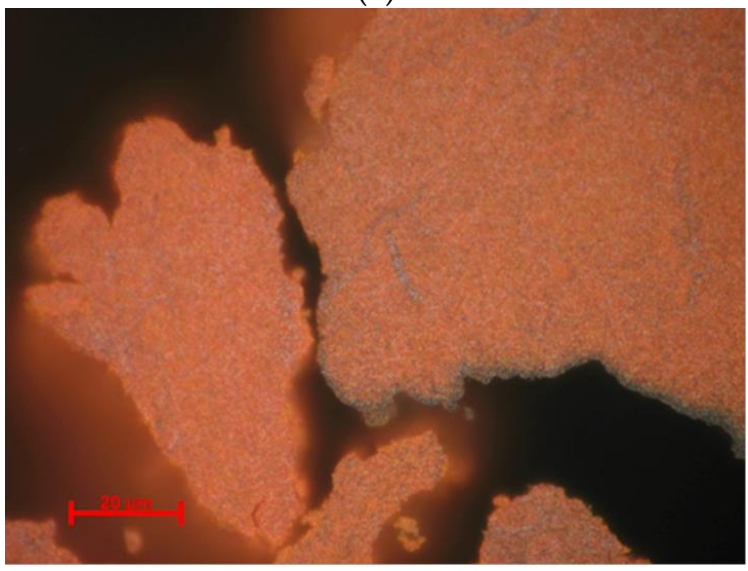

(c)

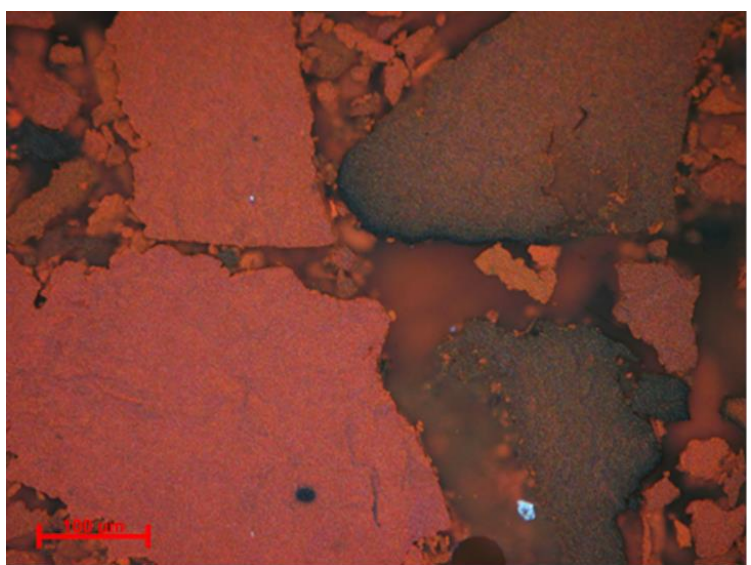

(b)

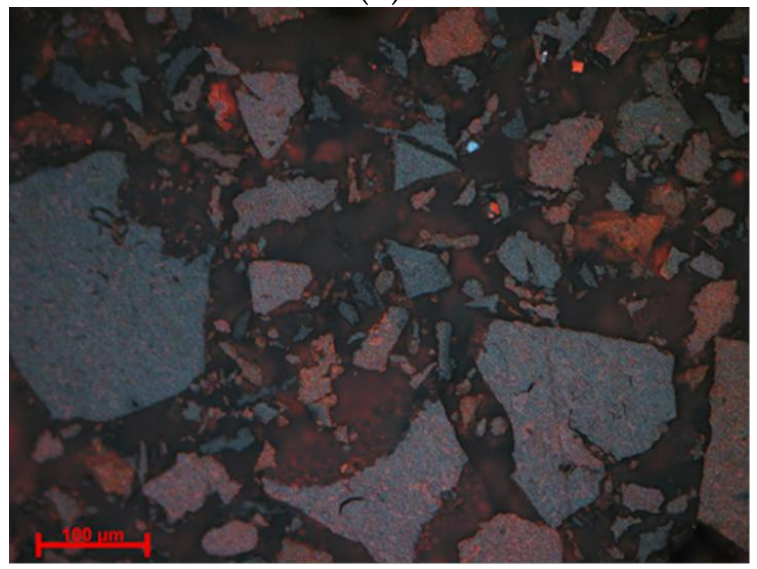

(d)

Figure 6. Reflected light, crossed Nicols. Optical micrographs of the thermally treated samples: (a) NV4-TT; (b) NV5-TT, Hematite (white, red internal reflections), magnetite (gray); (c) NV6-TT, Hematite (white, red internal reflections), magnetite (gray); (d) NV7-TT, Magnetite (gray), hematite (white, red internal reflections).

The resulted obtained from optical microscopy are in agreement with XRD analysis, showing that, after thermal treatment, samples consisted of: $>10 \%$ hematite and $\%$ magnetite in the case of NV4-TT sample; $~ 50 \%$ hematite and 50\% magnetite for NV5-TT sample; $>10 \%$ hematite in the case of NV6-TT sample; and $>10 \%$ of $\%$ magnetite and \% hematite for NV7-TT sample. In the case of NV4-TT sample, intense red reflexes characteristic of hematite can be observed, while the presence of magnetite is suggested by the grey areas. In most granules, magnetite and hematite are intimately associated but are not evenly distributed. The ratio between them is different depending on the area [50-53]. For NV5-TT sample, predominant areas of hematite (red color) and magnetite (grey color) are clearly delimited.

In sample NV6-TT, the distribution of magnetite on cracks is observed (Figure 6c). Larger hematite granules (white color) are formed in NV7-TT sample (Figure 6d). The presence of magnetite phase is confirmed by the gray areas. The two phases are relatively homogenous and uniformly distributed.

\subsubsection{SEM-EDS Characterization}

The existence of both hematite and magnetite phases in thermally treated samples is also demonstrated by SEM-EDS characterization. An example of phase distribution inside NV4-TT sample is shown in Figure 7. In Figure 7a, magnetite phase is represented by the small white areas and the cracks formed due to hematite reduction. Figure $7 \mathrm{~b}, \mathrm{~d}$ clearly show the distribution of $\mathrm{O}$ and Fe content along the line starting from the hematite predominant area $(\mathrm{M})$ to magnetite predominant area $(\mathrm{H})$. 
It can be seen that the oxygen content decreases with the transition from $\mathrm{H}(30 \% \mathrm{O})$ to $\mathrm{M}(27.6 \%)$, as expected.

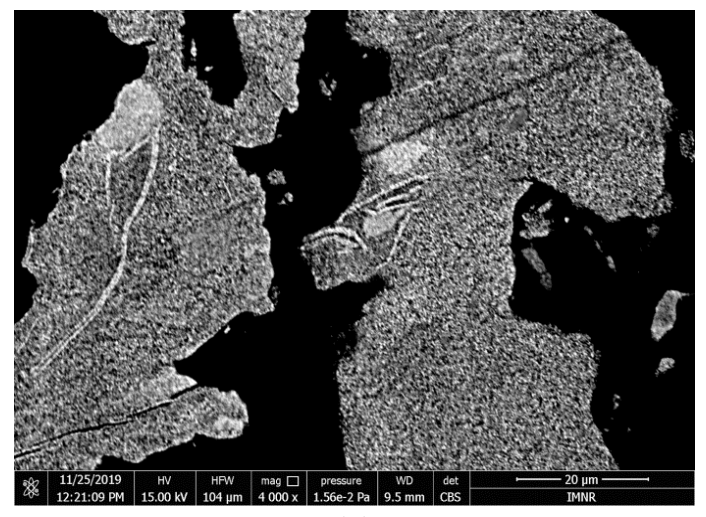

(a)

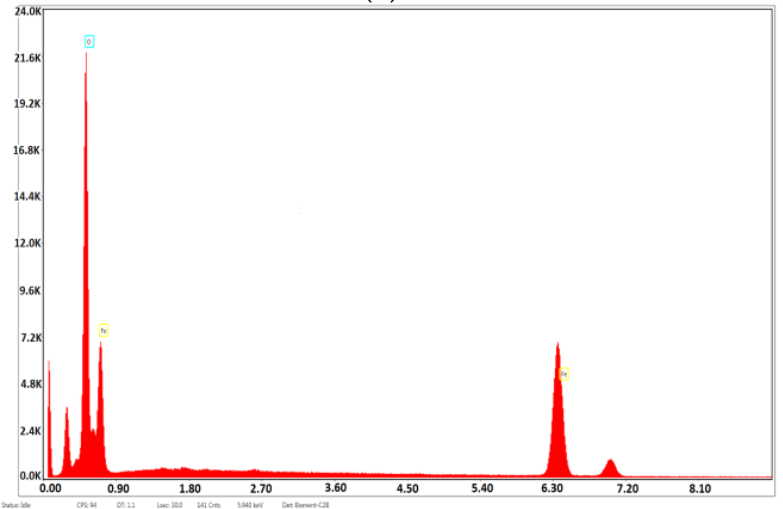

(c)

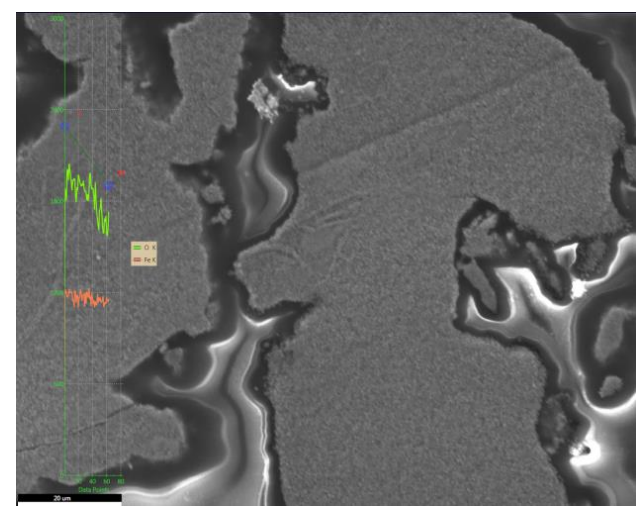

(b)

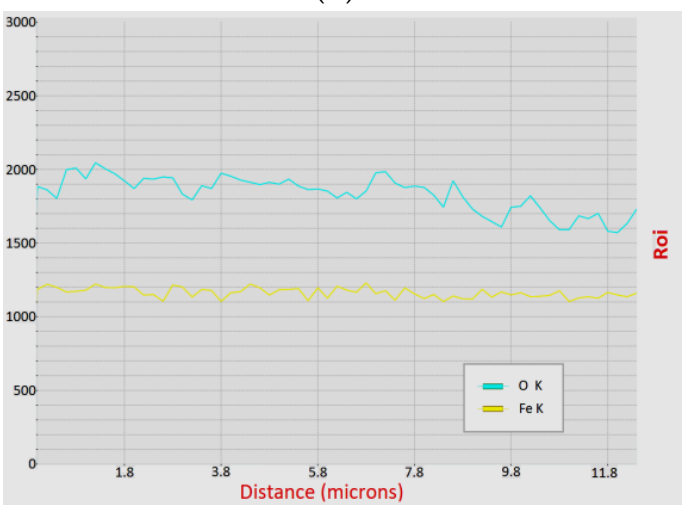

(d)

Figure 7. SEM-EDS characterization of a hematite sample after thermal treatment at $680{ }^{\circ} \mathrm{C}(\mathrm{NV} 4-\mathrm{TT})$, embedded in EpoThin-Buehler resin: (a) micrograph by scanning electron microscopy (SEM) collected using Circular Backscatter Detector (CBS); magnification 4000x; scale bar $20 \mu \mathrm{m}$; (b) line between hematite and magnetite areas; (c) elemental analysis by energy dispersive X-ray spectroscopy (EDS); (d) distribution of $\mathrm{O}$ (turquoise) and $\mathrm{Fe}$ (yellow) content along the line between hematite and magnetite areas from left to right.

\subsection{Magnetic Characterization}

ZFC-FC curves and hysteresis loops at $10 \mathrm{~K}$ and $300 \mathrm{~K}$ are shown in Figures 8 and 9 for samples NV4 and NV4-TT. As a direct observation related to sample NV4 is the step-like increment of the magnetization in the ZFC curve at about $250 \mathrm{~K}$ and the permanently higher magnetization in the FC curve as compared to the ZFC one. The first aspect is related to the well-known Morin transition tacking place in the corundum structure of hematite, pointing to a change in the spin structure from antiferromagnetic (at low temperature) to a weak ferromagnetic one at room temperature [56]. Note that such a transition assumes a well crystallized hematite with a nanoparticle size ranging out from the superparamagnetic regime. However, the upper variation of the FC curve over the ZFC one supports the idea of monodomain like nanoparticles, in agreement with sizes of tens of nanometers as obtained from XRD. The change from an antiferromagnetic spin structure at low temperature to a weak ferromagnetic one at room temperature is related to the appearance of a slight canting along the [111] trigonal direction of the spins initially antiferomagnetic coupled in the (111) plane at low temperature [56]. The main antiferromagnetic behavior is also sustained by the lack of saturation with continuous (linear) increment of the magnetization in higher fields as well as by the very low values of magnetization, whereas the above-mentioned change in the spin structure is sustained by the higher magnetization in the loop at $300 \mathrm{~K}$ as compared to the loop at $10 \mathrm{~K}$ (see Figure 8a,b). 

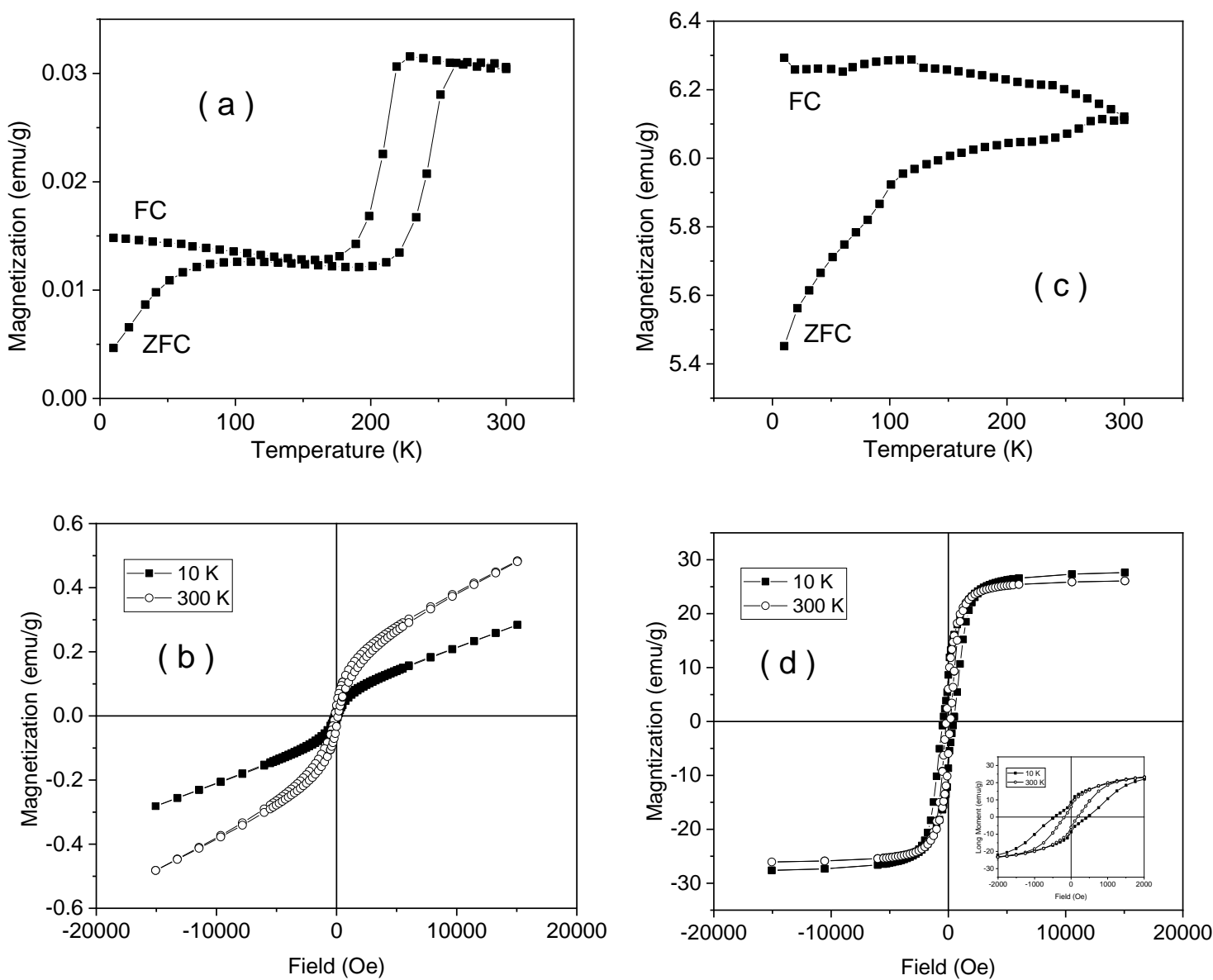

Figure 8. Zero Field Cooled-Field Cooled (ZFC-FC) curves collected in 80 Oe $(0.008 \mathrm{~T}$ magnetic field induction) direct current (DC) applied field (a) and hysteresis loops (b) for sample NV4, similar ZFC-FC curve (c) and hysteresis loops (d) for sample NV4-TT.

Note the drastically changed ZFC-FC curves and hysteresis loops of sample NV4-TT as compared to the case of sample NV4 (see Figure 8c,d). First of all, the branching aspect with continuous increase of the ZFC curve vs. temperature and continuous increase of FC magnetization at decreasing temperature stand for magnetic mono-domain nanoparticles with blocking temperatures well above $300 \mathrm{~K}$. The small jumps on both ZFC and FC curves evidenced in the range of 100-120 K and 230-250 K suggest the formation of poorly crystallized magnetite phases (with Verwey temperature of about $120 \mathrm{~K}$ ) and a rest of hematite nanoparticles (with a Morin temperature of about $250 \mathrm{~K}$ ) [56,57]. This aspect is also definitely supported by the value of saturation magnetization, e.g., about $28 \mathrm{emu} / \mathrm{g}$ $\left(3.51 \times 10^{-5} \mathrm{Tm}^{3} / \mathrm{kg}\right)$ at $10 \mathrm{~K}$ as resulting from the loops presented in Figure $8 \mathrm{~d}$. Assuming that a well crystallized magnetite might have some $90 \mathrm{emu} / \mathrm{g}\left(11 \times 10^{-5} \mathrm{Tm}^{3} / \mathrm{kg}\right)$ saturation magnetization [45,57], it results in a rough amount of a maximum of $28 \%$ of magnetite in the sample. In the inset of the same figure, the loops over a narrower field range are presented, pointing for the presence of two magnetic phases, the one giving the dominant magnetic signal having a coercive field of about 450 Oe (0.045 T magnetic field induction) at $10 \mathrm{~K}$ and $190 \mathrm{Oe}$ (0.019 T magnetic field induction) at $300 \mathrm{~K}$, specific to magnetite.

The magnetic measurements obtained on samples NV6 and NV6-TT are shown in Figure 9. The first aspect derived from ZFC-FC measurement is the lack of any trace of nanoparticle related dynamical behavior of superspins in the NV6 system (i.e., no increment of the ZFC curve at low temperatures).

This suggests that, even in a case of nanoparticle-like morphology, these interact magnetically not only by weak dipolar interactions, but they are much stronger. 

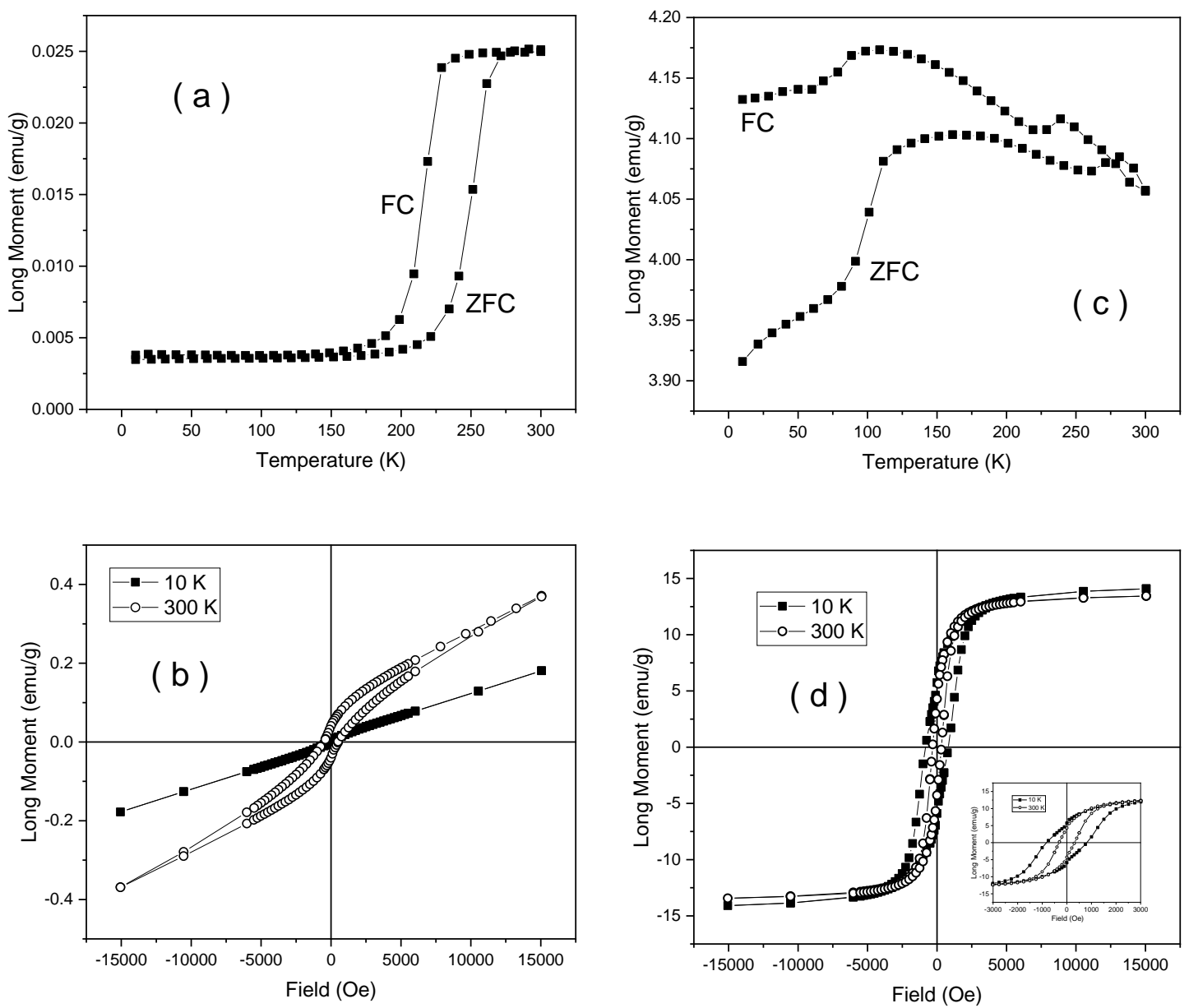

Figure 9. ZFC-FC curves collected in 80 Oe (0.008 T magnetic field induction) DC applied field (a) and hysteresis loops (b) for sample NV6, similar ZFC-FC curve (c) and hysteresis loops (d) for sample NV6-TT.

On the other hand, the Morin transition is very clearly evidenced in this sample together with its interesting temperature loop (Figure 9a,b). It is to be concluded that well-formed and strongly interacting hematite particles are found, giving rise to an overall structure of magnetic domains at $300 \mathrm{~K}$, as evidenced via the corresponding hysteresis loop in Figure $9 \mathrm{~b}$.

Note the same characteristics of the hysteresis loops for this sample as for sample NV4, except a much larger coercive field at $300 \mathrm{~K}$, namely $500 \mathrm{Oe}$ ( $0.05 \mathrm{~T}$ magnetic field induction) as compared to 140 Oe (0.014 T magnetic field induction), in case of negligible coercive fields at $10 \mathrm{~K}$ for both samples.

The thermal annealing changes again the phase composition as clearly evidenced from Figure 9c, where again two magnetic transitions can be deduced from both ZFC and FC curves (the Verwey transition at 100-120 K and Morin transition at 220-260 K). Both transitions are much better evidenced as compared to sample NV4-TT (see Figure 9c) in conditions of a much lower magnetization at saturation of only $15 \mathrm{emu} / \mathrm{g}\left(1.88 \times 10^{-5} \mathrm{Tm}^{3} / \mathrm{kg}\right)$ at $10 \mathrm{~K}$ (see Figure $9 \mathrm{~d}$ ). This means that the amount of magnetite is lower in sample NV6-TT (e.g. less than 17\%), but it is of much better quality (e.g., better crystallized) than in the case of sample NV4-TT. This fact is supported also by the enhanced coercive fields in this sample, e.g., of $840 \mathrm{Oe}(0.084 \mathrm{~T}$ magnetic field induction) at $10 \mathrm{~K}$ and $320 \mathrm{Oe}(0.032 \mathrm{~T}$ magnetic field induction) at $300 \mathrm{~K}$.

Finally, the magnetic results on samples NV7 and NV-7TT are shown in Figure 10. 

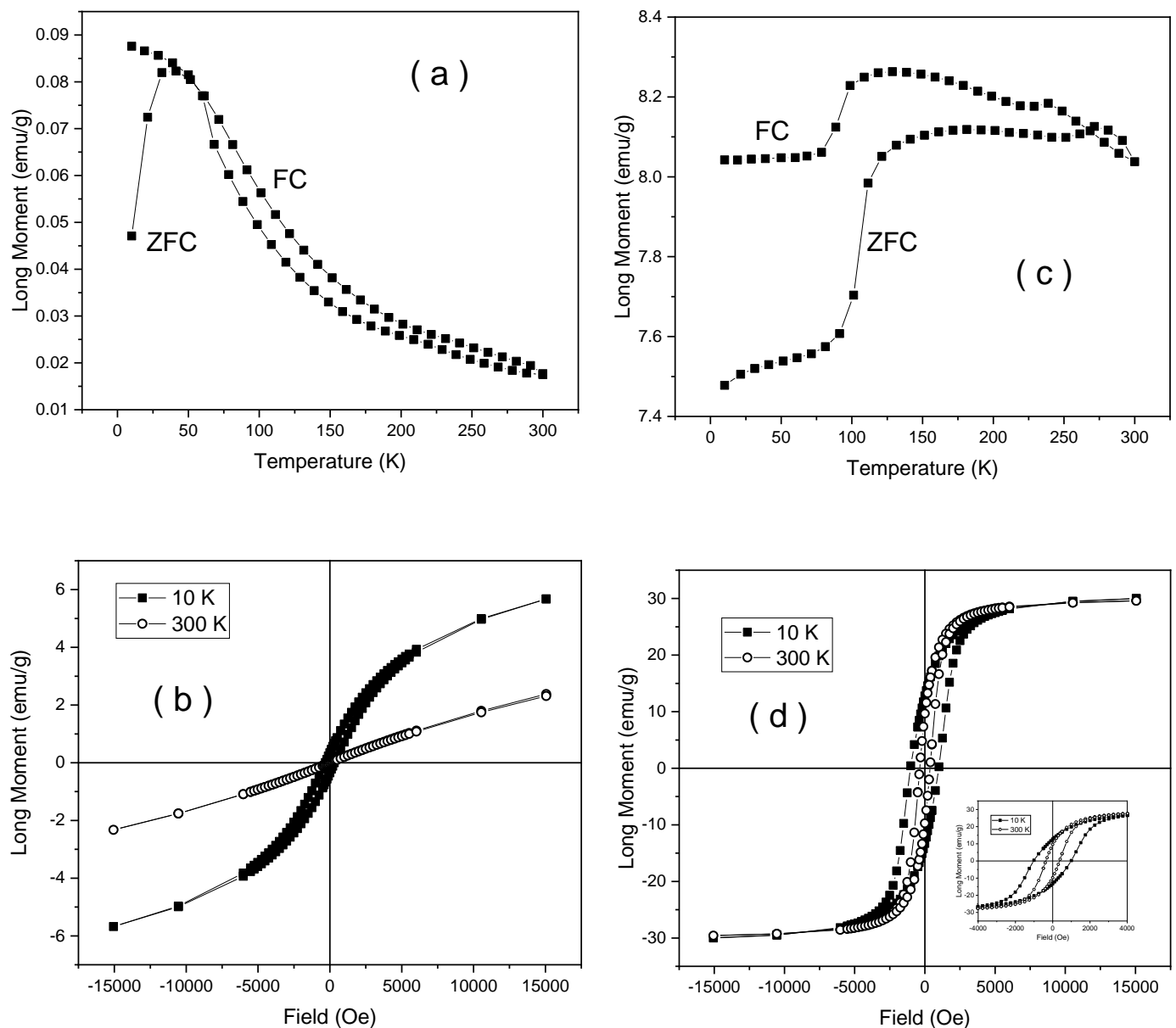

Figure 10. ZFC-FC curves collected in 80 Oe (0.008 T magnetic field induction) DC applied field (a) and hysteresis loops (b) for sample NV7, similar ZFC-FC curve (c) and hysteresis loops (d) for sample NV7-TT.

The first aspect to be mentioned is the higher magnetization and the trend of the ZFC curve of NV7 sample (Figure 10a) with a maximum at a temperature of about $50 \mathrm{~K}$ specific to nanoparticulate systems with enhanced magnetic moments (e.g., no antiferromagnetic coupling) and a blocking temperature of $50 \mathrm{~K}$. However, the type of branching supports also the presence of an additional magnetic phase which intermediates a sort of inter-particle interactions. The magnetization values in high fields are, according to Figure 10b, an order of magnitude higher than in the case of the previous samples, giving support for a magnetic phase different from hematite. This additional phase that is magnetic at low temperatures and with paramagnetic/superparamagnetic behavior at $300 \mathrm{~K}$ can be assigned to a Fe oxo-hydroxide, whose nature might be better determined by Mössbauer spectroscopy.

Finally, following the thermal treatment, the specific magnetite and hematite phases are again evidenced through the specific Verwey and Morin transitions evidenced by the ZFC-FC measurements on sample NV7-TT (Figure 10c). The saturation magnetization is close to $30 \mathrm{emu} / \mathrm{g}\left(3.77 \times 10^{-5} \mathrm{Tm}^{3} / \mathrm{kg}\right)$ at both $10 \mathrm{~K}$ and $300 \mathrm{~K}$ (Figure 10d), proving quite large magnetite particle sizes). Together with the well pronounced jump along the Verwey transition, this result supports the formation of well crystallized and relatively large magnetite nanoparticles with a relative concentration close to $33 \mathrm{wt} \%$.

Mössbauer spectra of samples NV4 and NV4-TT (at $6 \mathrm{~K}$ and $300 \mathrm{~K}$ for each sample) are shown in Figure 11 ( $\mathrm{a}$ and $\mathrm{b}$ for NV4; $\mathrm{c}$ and d for NV4-TT). Mössbauer spectra of samples NV5, NV6, and NV7 (at $10 \mathrm{~K}$ and $300 \mathrm{~K}$ for each sample) are shown in Figure 12 ( $\mathrm{a}, \mathrm{b}$ for NV5; c, d for NV6; and e, $\mathrm{f}$ for NV7). It can be observed that the as prepared sample NV4 consists at $6 \mathrm{~K}$ and $300 \mathrm{~K}$ in only one sextet component with hyperfine parameters specific to hematite (e.g., hyperfine magnetic field of $54 \mathrm{~T}$ at $6 \mathrm{~K}$ and $51 \mathrm{~T}$ at $300 \mathrm{~K}$ ). After the thermal treatment, an additional phase fitted by one Mössbauer 
sextet at $6 \mathrm{~K}$ and two Mossbauer sextets at $300 \mathrm{~K}$ are observed. The hyperfine parameters of this new phase are specific to magnetite (e.g., at $300 \mathrm{~K}$ the hyperfine magnetic fields are of $49.2 \mathrm{~T}$ and $46.3 \mathrm{~T}$ ). The magnetite represents $24 \%$ from the Fe phases, with the other $76 \%$ remaining as hematite. Note the very defect structure of magnetite with an occupation of 1:1 on octahedral to tetrahedral positions.

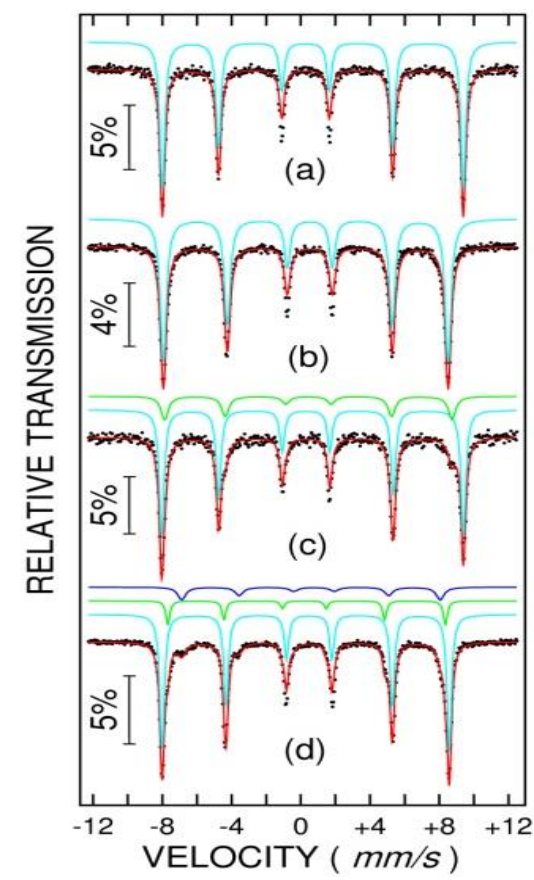

Figure 11. Mössbauer spectra of sample NV4 at $6 \mathrm{~K}$ and $300 \mathrm{~K}(\mathbf{a}, \mathbf{b})$ and NV4-TT (c,d). Black dots represent the experimental data and the red curve is the theoretical fit as obtained by superposing the spectral components represented above each spectrum.

Concerning the behavior of the rest of as prepared samples, NV5 is also represented by only one component with specific hyperfine parameters for hematite, NV6 presents an additional component ( $3 \mathrm{wt} \%$ ) with hyperfine parameters specific to goethite (e.g., $50.3 \mathrm{~T}$ at $6 \mathrm{~K}$ and $38.2 \mathrm{~T}$ at $300 \mathrm{~K}$ ), in excellent agreement with the XRD characterization and, finally, sample NV7 is formed by $56 \%$ of hematite and $44 \%$ of goethite, according to the low temperature Mössbauer spectrum (note that MS is more sensitive to the composition of the Fe phases as compared to XRD). At RT, about $20 \%$ of goethite becomes superparamagnetic within the Mössbauer time window, again in excellent agreement with the magnetic measurements pointing for superparamagnetic behavior of goethite nanoparticles at higher temperatures.

The as evidenced type of involved magnetic phases and their distribution in the analyzed samples are shown in Table 6 and Figure 13.

Table 6. Phase distribution in all samples.

\begin{tabular}{cc}
\hline Sample Name & Phase Type \\
\hline NV4 & hematite \\
NV4-TT & Hematite + magnetite \\
NV5 & hematite \\
NV5-TT & Hematite + magnetite \\
NV6 & Hematite + goethite \\
NV6-TT & Hematite + magnetite \\
NV7 & Hematite + goethite \\
NV7-TT & Hematite + magnetite \\
\hline
\end{tabular}




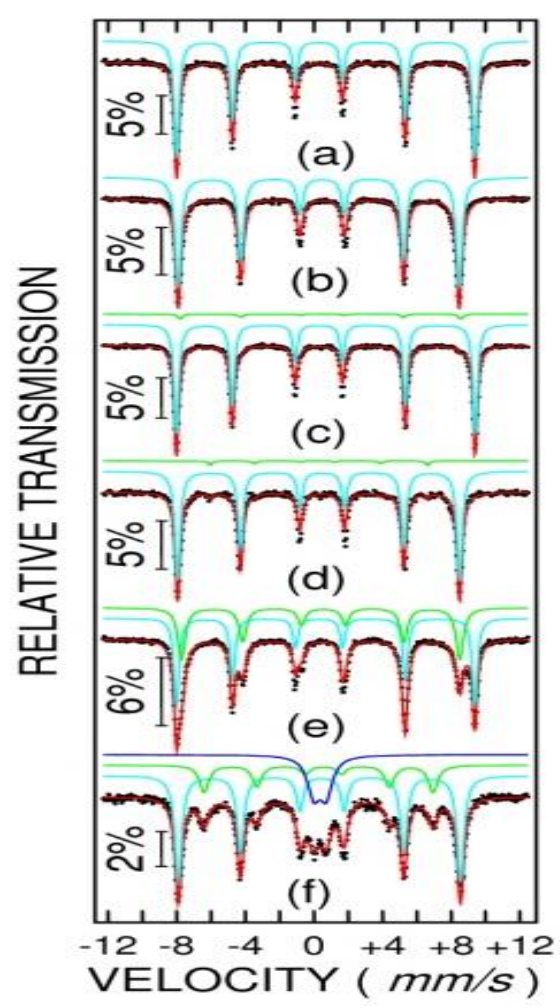

Figure 12. Mössbauer spectra of sample NV5 at $6 \mathrm{~K}$ and $300 \mathrm{~K}(\mathbf{a}, \mathbf{b})$, NV6 (c,d) and NV7 (e,f). Black dots represent the experimental data and the red curve is the theoretical fit as obtained by superposing the spectral components represented above each spectrum.

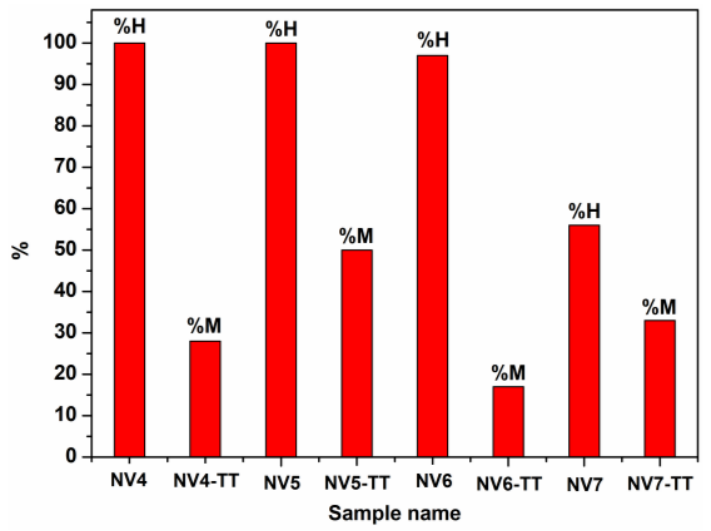

Figure 13. Distribution of hematite $(\mathrm{H})$ and magnetite $(\mathrm{M})$ in all iron oxide samples synthesized by hydrothermal method in high pressure conditions, before $(\mathrm{NVx})$ and after thermal treatment at $680{ }^{\circ} \mathrm{C}$ $(\mathrm{NVx}-\mathrm{TT})$.

\section{Conclusions}

The influence of synthesis pressure on crystalline structure of iron oxide prepared by hydrothermal method was studied. It has been found that, for lower pressure values (less than 100 bar), iron oxide is predominantly formed as hematite, while, at pressures above 100 bar, the major crystalline phase is goethite. The complex thermal analysis by the DSC method revealed the polymorphic changes of iron oxides at different temperatures. Thermal stability of hydrothermal synthesized nanoparticles under various experimental conditions has been demonstrated by performing heating/cooling cycles.

The specific magnetite and hematite phases have been evidenced in all thermally treated samples through XRD, optical microscopy, SEM characterization, and the specific Verwey and Morin transitions 
evidenced by the ZFC-FC measurements. ZFC and FC curves suggested the formation of poorly crystallized magnetite (maximum 28\%) phases (with Verwey temperature of about $120 \mathrm{~K}$ ) and a rest of hematite nanoparticles (with a Morin temperature of about $250 \mathrm{~K}$ ) in the case of NV4-TT sample. The amount of magnetite is lower in sample NV6-TT (e.g., less than 17\%), but it is much better crystallized than in the case of sample NV4-TT. The formation of well crystallized and relatively large magnetite nanoparticles with a relative concentration close to $33 \mathrm{wt} \%$ was observed in the case of NV7-TT sample. The results obtained by Mössbauer characterization are in excellent agreement with the XRD and MO characterization, showing the formation of one component in the case of samples prepared at lower pressure $(<100$ bar)-hematite (with partial transformation in magnetite after thermal treatment), and the appearance of goethite for samples synthesized at pressures $>100$ bar. It has been proven that the phase composition and magnetic parameters of the samples can be tuned via the applied pressure during the hydrothermal synthesis as well as by subsequent annealing conditions. Among the as prepared samples, of very weak ferromagnetic contributions, one order of magnitude higher magnetization is obtained for sample NVT synthesized under the highest applied pressure (e.g. 1000 bar). The same sample also provides, by a subsequent annealing treatment, the highest amount of good quality magnetite leading to a magnetization at saturation of $30 \mathrm{emu} / \mathrm{g}$ $\left(3.77 \times 10^{-5} \mathrm{Tm}^{3} / \mathrm{kg}\right)$ and a coercive field of $1000 \mathrm{Oe}(0.1 \mathrm{~T}$ magnetic field induction) at $10 \mathrm{~K}$ and 450 Oe (0.045 T magnetic field induction) at $300 \mathrm{~K}$, already convenient for various applications.

Author Contributions: Conceptualization, L.M.C. and R.M.P.; Methodology, L.M.C., R.M.P., V.K., and F.S.; Investigation, D.V.D., I.A.T., N.I., F.S.; Writing-Original Draft Preparation, L.M.C.; Writing-Review and Editing, R.M.P. and V.K.; Project Administration, R.M.P.; Funding Acquisition, R.M.P. and V.K. All authors have read and agreed to the published version of the manuscript.

Funding: This research was funded by ERANET-EURONANOMED 2 project, acronym NANOVIBER, UEFISCDI ctr. no.1/2017 (IMNR) and PN-III-P1-1.2-PCCDI-2017-0062 (NIMP).

Conflicts of Interest: The authors declare no conflict of interest.

\section{References}

1. Magro, M.; Vianello, F. Bare iron oxide nanoparticles: Surface tunability for biomedical, sensing and environmental applications. Nanomaterials 2019, 9, 1608. [CrossRef] [PubMed]

2. Mai, T.; Hilt, J.Z. Functionalization of iron oxide nanoparticles with small molecules and the impact on reactive oxygen species generation for potential cancer therapy. Colloid Surf. A 2019, 576, 9-14. [CrossRef]

3. Morel, M.J.; Mosquera, E.; Sáez, P. Surface modification and polymerization on iron oxide nanoparticles obtained from mineral magnetite. Surf. Interfaces 2019, 17, 100349. [CrossRef]

4. Gupta, A.K.; Gupta, M. Synthesis and surface engineering of iron oxide nanoparticles for biomedical applications. Biomaterials 2005, 26, 3995-4021. [CrossRef]

5. Rabinca, A.; Buleandra, M.; Tache, F.; Mihailciuc, C.; Ciobanu, A.; Stefanescu, D.; Ciucu, A. Voltammetric method for simultaneous determination of L-dopa and benserazide. Curr. Anal. Chem. 2017, 13, 218-224. [CrossRef]

6. Ciobanu, A.M.; Popa, C.; Marcu, M.; Ciobanu, C.F. Psychotic depression due to giant condyloma Buschke-Löwenstein tumors. Rom. J. Morphol. Embryol. 2014, 55, 189-195.

7. González-Gómez, M.A.; Belderbos, S.; Yañez-Vilar, S.; Piñeiro, Y.; Cleeren, F.; Bormans, G.; Deroose, C.M.; Gsell, W.; Himmelreich, U.; Rivas, J. Development of superparamagnetic nanoparticles coated with polyacrylic acid and aluminum hydroxide as an efficient contrast agent for multimodal imaging. Nanomaterials 2019, 9, 1626. [CrossRef]

8. Kirubha, S.P.A.; Rajput, A. Enhancement of thermal imaging by iron oxide nanoparticle—Preliminary study. Biocatal. Agric. Biotechnol. 2019, 17, 352-360. [CrossRef]

9. Abd Elrahman, A.A.; Mansour, F.R. Targeted magnetic iron oxide nanoparticles: Preparation, functionalization and biomedical application. J. Drug Deliv. Sci. Technol. 2019, 52, 702-712. [CrossRef]

10. Roca, A.G.; Gutiérrez, L.; Gavilán, H.; Brollo, M.E.F.; Veintemillas-Verdaguer, S.; Morales, M.D. Design strategies for shape-controlled magnetic iron oxide nanoparticles. Adv. Drug Deliv. Rev. 2019, 138, 68-104. [CrossRef] 
11. Liyanage, P.Y.; Hettiarachchi, S.D.; Zhou, Y.Q.; Ouhtit, A.; Seven, E.S.; Oztan, C.Y.; Celik, E.; Leblanc, R.M. Nanoparticle-mediated targeted drug delivery for breast cancer treatment. BBA Rev. Cancer 2019, 1871, 419-433. [CrossRef] [PubMed]

12. Hola, K.; Markova, Z.; Zoppellaro, G.; Tucek, J.; Zboril, R. Tailored functionalization of iron oxide nanoparticles for MRI, drug delivery, magnetic separation and immobilization of biosubstances. Biotechnol. Adv. 2015, 33, 1162-1176. [CrossRef] [PubMed]

13. Mahmoudi, M.; Sant, S.; Wang, B.; Laurent, S.; Sen, T. Superparamagnetic iron oxide nanoparticles (SPIONs): Development, surface modification and applications in chemotherapy. Adv. Drug Deliv. Rev. 2011, 63, $24-46$. [CrossRef] [PubMed]

14. Hu, H.; Yuan, Y.; Lim, S.; Wang, C.H. Phase structure dependence of magnetic behaviour in iron oxide nanorods. Mater. Des. 2020, 185, 108241. [CrossRef]

15. Nikitin, A.; Khramtsov, M.; Garanina, A.; Mogilnikov, P.; Sviridenkova, N.; Shchetinin, I.; Savchenko, A.; Abakumov, M.; Majouga, A. Synthesis of iron oxide nanorods for enhanced magnetic hyperthermia. J. Magn. Magn. Mater. 2019, 469, 443-449. [CrossRef]

16. Rybka, J.D. Radiosensitizing properties of magnetic hyperthermia mediated by superparamagnetic iron oxide nanoparticles (SPIONs) on human cutaneous melanoma cell lines. Rep. Pract. Oncol. Radiother. 2019, 24, 152-157. [CrossRef]

17. Oliveira, A.; Hneda, M.L.; Fernandez-Outon, L.E.; De Sousa, E.M.B.; Ardisson, J.D. Synthesis and characterization of nanocomposites based on rare-earth orthoferrites and iron oxides for magnetic hyperthermia applications. Ceram. Int. 2019, 45, 17920-17929. [CrossRef]

18. Yasemian, A.R.; Kashi, M.A.; Ramazani, A. Surfactant-free synthesis and magnetic hyperthermia investigation of iron oxide $\left(\mathrm{Fe}_{3} \mathrm{O}_{4}\right)$ nanoparticles at different reaction temperatures. Mater. Chem. Phys. 2019, 230, 9-16. [CrossRef]

19. Abenojar, E.C.; Wickramasinghe, S.; Bas-Concepcion, J.; Samia, A.C.S. Structural effects on the magnetic hyperthermia properties of iron oxide nanoparticles. Prog. Nat. Sci. Mater. 2016, 26, 440-448. [CrossRef]

20. Soares, P.I.P.; Laia, C.A.T.; Carvalho, A.; Pereira, L.C.J.; Coutinho, J.T.; Ferreira, I.M.M.; Novo, C.M.M.; Borges, J.P. Iron oxide nanoparticles stabilized with a bilayer of oleic acid for magnetic hyperthermia and MRI applications. Appl. Surf. Sci. 2016, 383, 240-247. [CrossRef]

21. Ebrahimisadr, S.; Aslibeiki, B.; Asadi, R. Magnetic hyperthermia properties of iron oxide nanoparticles: The effect of concentration. Phys. C 2018, 549, 119-121. [CrossRef]

22. Elsayed, W.E.M.; Al-Hazmi, F.S.; Memesh, L.S.; Bronstein, L.M. A novel approach for rapid green synthesis of nearly mono-disperse iron oxide magnetic nanocubes with remarkable surface magnetic anisotropy density for enhancing hyperthermia performance. Colloid Surf. A 2017, 529, 239-245. [CrossRef]

23. Gyergyek, S.; Makovec, D.; Jagodič, M.; Drofenik, M.; Schenk, K.; Jordan, O.; Kovac, J.; Drazic, G.; Hofmann, H. Hydrothermal growth of iron oxide NPs with a uniform size distribution for magnetically induced hyperthermia: Structural, colloidal and magnetic properties. J. Alloy. Compd. 2017, 694, 261-271. [CrossRef]

24. Wu, W.; He, Q.; Jiang, C. Magnetic iron oxide nanoparticles: Synthesis and surface functionalization strategies. Nanoscale Res. Lett. 2008, 3, 397-415. [CrossRef] [PubMed]

25. Miola, M.; Ferraris, S.; Pirani, F.; Multari, C.; Bertone, E.; Žužek Rožman, K.; Kostevšek, N.; Verné, E. Reductant-free synthesis of magnetoplasmonic iron oxide-gold nanoparticles. Ceram. Int. 2017, 43, 15258-15265. [CrossRef]

26. Gholamia, L.; Kazemi Oskueeb, R.; Tafaghodic, M.; Ramezani Farkhanic, A.; Darroudid, M. Green facile synthesis of low-toxic superparamagnetic iron oxide nanoparticles (SPIONs) and their cytotoxicity effects toward Neuro2A and HUVEC cell lines. Ceram. Int. 2018, 44, 9263-9268. [CrossRef]

27. Buchman, J.T.; Pho, T.; Rodriguez, R.S.; Feng, Z.V.; Haynes, C.L. Coating iron oxide nanoparticles with mesoporous silica reduces their interaction and impact on S. oneidensis MR-1. Chemosphere 2019, 237, 124511. [CrossRef]

28. Tadic, M.; Kralj, S.; Kopanja, L. Synthesis, particle shape characterization, magnetic properties and surface modification of superparamagnetic iron oxide nanochains. Mater. Charact. 2019, 148, 123-133. [CrossRef]

29. Ghasemi, A.; Jafari, S.; Saeidi, J.; Mohtashami, M.; Salehi, I. Synthesis and characterization of polyglycerol coated superparamagnetic iron oxide nanoparticles and cytotoxicity evaluation on normal human cell lines. Colloid Surf. A 2018, 551, 128-136. [CrossRef] 
30. Medeiros, S.F.; Filizzola, J.O.C.; Fonseca, V.F.M.; Oliveira, P.F.M.; Silva, T.M.; Elaissari, A.; Santos, A.M. Synthesis and characterization of stable aqueous dispersion of functionalized double-coated iron oxide nanoparticles. Mater. Lett. 2015, 160, 522-525. [CrossRef]

31. Ruan, C.; Wang, J.; Gao, M.; Zhao, G. The influence of structural size on thermal stability in single crystalline hematite uniform nano/micro-cubes. Mater. Chem. Phys. 2016, 183, 158-164. [CrossRef]

32. Lee, J.; Kwon, S.G.; Park, J.G.; Hyeon, T. Size dependence of metal-insulator transition in stoichiometric $\mathrm{Fe}_{3} \mathrm{O}_{4}$ nanocrystals. Nano Lett. 2015, 15, 4337-4342. [CrossRef] [PubMed]

33. Li, M.; Altman, E.I. Cluster-size dependent phase transition of Co oxides on Au(111). Surf. Sci. 2014, 619, L6-L10. [CrossRef]

34. Mondal, R.A.; Murty, B.S.; Murthy, V.R.K. Grain size dependent phase transition and superparaelectric behavior of ferroelectric BST. Phys. B 2015, 461, 10-16. [CrossRef]

35. Zhu, C.B.; Gu, L.; Suo, L.; Popovic, J.; Li, H.; Ikuhara, Y.; Maier, J. Size-dependent staging and phase transition in $\mathrm{LiFePO}_{4} / \mathrm{FePO}_{4}$. Adv. Funct. Mater. 2014, 24, 312-318. [CrossRef]

36. Yan, X.Z.; Ren, X.T.; He, D.; Chen, B.; Yang, W. Mechanical behaviors and phase transition of $\mathrm{Ho}_{2} \mathrm{O}_{3}$ nanocrystals under high pressure. J. Appl. Phys. 2014, 116, 033507. [CrossRef]

37. Zhang, S.X.; Kim, I.S.; Lauhon, L.J. Stoichiometry engineering of monoclinic to rutile phase transition in suspended single crystalline vanadium dioxide nanobeams. Nano Lett. 2011, 11, 1443-1447. [CrossRef]

38. Spencer, E.C.; Ross, N.L.; Olsen, R.E.; Huang, B.; Kolesnikov, A.I.; Woodfield, B.F. Thermodynamic properties of $\alpha-\mathrm{Fe}_{2} \mathrm{O}_{3}$ and $\mathrm{Fe}_{3} \mathrm{O}_{4}$ nanoparticles. J. Phys. Chem. C 2015, 119, 9609-9616. [CrossRef]

39. Paolone, A.; Angelucci, M.; Panero, S.; Betti, M.G.; Mariani, C. Thermal stability and reduction of iron oxide nanowires at moderate temperatures. Beilstein J. Nanotechnol. 2014, 5, 323-328. [CrossRef]

40. Cendrowski, K.; Sikora, P.; Zielinska, B.; Horszczaruk, E.; Mijowska, E. Chemical and thermal stability of core-shelled magnetite nanoparticles and solid silica. Appl. Surf. Sci. 2017, 407, 391-397. [CrossRef]

41. Barnakov, Y.A.; Yu, M.H.; Rosenzweig, Z. Manipulation of the magnetic properties of magnetite silica nanocomposite materials by controlled stober synthesis. Langmuir 2005, 21, 7524-7527. [CrossRef] [PubMed]

42. Kalska-Szostko, B.; Wykowska, U.; Satula, D.; Nordblad, P. Thermal treatment of magnetite nanoparticles. Beilstein J. Nanotechnol. 2015, 6, 1385-1396. [CrossRef] [PubMed]

43. Popescu, M.; Piticescu, R.M.; Vasile, E.; Taloi, D.; Petriceanu, M.; Stoiciu, M.; Badilita, V. The influence of synthesis parameters on $\mathrm{FeO}(\mathrm{OH}) / \mathrm{Fe}_{2} \mathrm{O}_{3}$ formation by hydrothermal techniques. Z. Nat. B 2010, 65, 1024-1032. [CrossRef]

44. Buchner, M.; Höfler, K.; Henne, B.; Ney, V.; Ney, A. Tutorial: Basic principles, limits of detection, and pitfalls of highly sensitive SQUID magnetometry for nanomagnetism and spintronics. J. Appl. Phys. 2018, 124, 161101. [CrossRef]

45. Kuncser, V.; Palade, P.; Kuncser, A.; Greculeasa, S.; Schinteie, G. Size Effects in Nanostructures Basics and Applications; Springer: Berlin/Heidelberg, Germany, 2014; pp. 169-237.

46. Water Structure and Science. Available online: http://www1.lsbu.ac.uk/water/physical_anomalies.html (accessed on 16 November 2019).

47. Cornell, R.M.; Schwertmann, U. The Iron Oxides: Structure, Properties, Reactions, Occurences and Uses; Wiley-VCH Verlag GmbH \& Co. KGaA: Weinheim, Germany, 2003; pp. 365-382.

48. Betancur, A.F.; Pérez, F.R.; Del Mar Correa, M.; Barrero, C.A. Quantitative approach in iron oxides and oxihydroxides by vibrational analysis. Opt. Pura Apl. 2012, 45, 269-275. [CrossRef]

49. Lu, B. Surface Reactivity of Hematite Nanoparticles. Master's Thesis, Umeå University, Umeå, Sweden, 2014.

50. Ramdohr, P. The Ore Minerals and Their Intergrowths, 1st ed.; Pergamon Press: Braunschweig, Germany, 1969; pp. 878-1074.

51. Winchell, A.N. Elements of Optical Microscopy: An Introduction to Microscopic Petrography; John Wiley \& Sons: New York, NY, USA, 1965; pp. 62-136.

52. Petruk, W. Applied Mineralogy in the Mining Industry; Elsevier: Ottawa, ON, Canada, 2000; pp. 149-183.

53. Ianovici, V.; Stiopol, V.; Constantinescu, E. Mineralogie; Editura Didactica si Pedagogica: Bucuresti, Romania, 1979.

54. Fouad, D.E.; Zhang, C.; El-Didamony, H.; Yingnan, L.; Mekuria, T.D.; Shah, A.H. Improved size, morphology and crystallinity of hematite $\left(\alpha-\mathrm{Fe}_{2} \mathrm{O}_{3}\right)$ nanoparticles synthesized via the precipitation route using ferric sulfate precursor. Results Phys. 2019, 12, 1253-1261. [CrossRef] 
55. Smykatz-Kloss, W. Differential Thermal Analysis: Application and Results in Mineralogy; Springer Science \& Business Media: Berlin, Germany, 2012.

56. Greenwood, N.N.; Gibb, T.G. Mössbauer Spectroscopy; Chapman and Hall Ltd.: London, UK, 1971.

57. Sandu, V.; Nicolescu, M.S.; Kuncser, V.; Popa, S.; Pasuk, I.; Ghica, G.; Sandu, E. Structure and magnetic properties of nanosized magnetite obtianed by glass recrystallization. J. Nanosci. Nanotechnol. 2012, 12, 1-8. [CrossRef]

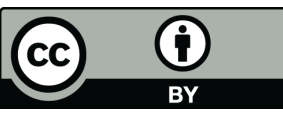

(C) 2020 by the authors. Licensee MDPI, Basel, Switzerland. This article is an open access article distributed under the terms and conditions of the Creative Commons Attribution (CC BY) license (http://creativecommons.org/licenses/by/4.0/). 